Review

\title{
Metal, Metalloid, and Oxide Nanoparticles for Therapeutic and Diagnostic Oncology
}

\author{
Mohammad Hossein Yazdi ${ }^{1,3}$, Zargham Sepehrizadeh ${ }^{1}$, Mehdi Mahdavi ${ }^{2,3}$, Ahmad Reza \\ Shahverdi $^{1,3}$, Mohammad Ali Faramarzi ${ }^{1}$ \\ ${ }^{1}$ Department of Pharmaceutical Biotechnology, Faculty of Pharmacy and Biotechnology Research Center, Tehran University of \\ Medical Sciences, P.O. Box 14155-6451, Tehran 1417614411, Iran. \\ ${ }^{2}$ Department of Immunology, Pasteur Institute of Iran, Tehran, Iran. \\ ${ }^{3}$ Recombinant Vaccine Research Center, Tehran University of Medical Sciences, P.O. Box 14155-6451, Tehran 1417614411, Iran.
}

Corresponding authors. E-mail: faramarz@tums.ac.ir, Tel: +98-21-66954712, Fax: +98-21-66954712 (A.M. Faramarzi); or E-mail: shahverd@tums.ac.ir, Tel: +98-21-66461178, Fax: +98-21-66461178 (A.R. Shahverdi).

Received: Sep. 24, 2016; Accepted: Nov. 21, 2016; Published: Dec. 6, 2016.

Citation: Mohammad Hossein Yazdi, Zargham Sepehrizadeh, Mehdi Mahdavi, Ahmad Reza Shahverdi, and Mohammad Ali Faramarzi, Metal, Metalloid, and Oxide Nanoparticles for Therapeutic and Diagnostic Oncology. Nano Biomed. Eng., 2016, 8(4): 246-267.

DOI: 10.5101/nbe.v8i4.p246-267.

\begin{abstract}
Nanoparticles have comprehensively affected various sights of human life. Through the wide range of claims about nanosized particles and their functions, biomedical applications are of much interest among health care researchers due to the nanoparticles' potential for use in the process of disease diagnosis, control and treatment. In this regard, inorganic nanoparticles, which have high potential in diagnostic and therapeutic systems, have recently received much attention in oncology. Although inorganic nanoparticles initially seemed an appropriate tool for cancer imaging and diagnosis, their ability to attack cancerous cells as anticancer drugs or carriers in other drugs has also demonstrated promising results. The present review primarily provides a brief survey of various studies in which metal nanoparticles such as gold, silver, iron oxide, and metalloid nanoparticles viz. tellurium and bismuth were exploited for therapeutic or diagnostic purposes in oncology. Then the application of selenium nanoparticles as a therapeutic agent against cancer in in vitro and in vivo studies is reviewed in detail. Although inorganic nanoparticles seem to be useful tools for cancer imaging and diagnosis, their potential for attacking cancerous cells as anticancer substances or even carriers for anticancer medications should not be underestimated.
\end{abstract}

Keywords: Metal NPs; Metalloid NPs; Tellurium NPs; Selenium NPs; Cancer diagnosis; Cancer treatment

\section{Introduction}

During the past decade, nanoparticles (NPs) have revolutionized various areas of science ranging from electronic to the environment and medicine. Although knowledge of NPs and their biomedical application is still in its infancy, nanomedicine has demonstrated numerous promising promotions in a wide variety of health-related problems in diagnostic and therapeutic systems. Despite vast advances in medicine in curing disease and improved life expectancy among patients, unresolved complications such as cancer stimulate researchers to find a desirable approach for overcoming the rest. This is where nanomedicine seems useful, 
and NPs open a new encouraging window. Inorganic NPs include metal and/or metalloid compounds that are converted from their bulk parents to nanomaterials through various methods. Chemical preparation of inorganic NPs is usually fast and compatible with a wide variety of materials $[1,2]$. However, this method is often considered energy intensive, and the application of toxic chemicals is a related concern [3].

Recently, biogenic production of NPs has received interest since it is not only a cost-effective method for obtaining nanomaterials but also eco-friendly and energy-efficient [4]. Likewise, the production of toxic materials is hindered by using this green biotechnological procedure. In contrast to the benefits of using the biogenic method for producing NPs, through the optimum growth condition (e.g., $\mathrm{pH}$, temperature, and nutrients), the difficult and timeconsuming procedure for extracting NPs at the end step, especially with the integration of microorganisms, is a drawback [4].

Biomedical application of metal and metalloid NPs has a broad spectrum ranging from imaging of the whole body to the potential treatment of cancer and investigation of the complex cellular events (Fig. 1) [5-7]. In fact, the increasing interest in using inorganic NPs in biomedicine is related to the exclusive size and shape-dependent optoelectronic properties of these materials [8] and their optoelectronic property abilities, which make them a unique tool for various biomedical applications [9]. Recently, NPs with diagnostic and therapeutic applications in oncology have attracted researchers' attention [10] in addition to influencing recent theragnostic advances in this field [11].

This review mainly surveys applications of metal inorganic NPs such as gold, silver, and iron oxide in cancer diagnosis and therapy through available publications. In addition, metalloid NPs such as tellurium and bismuth are reviewed, and selenium NPs are discussed in more detail in terms of anticancer properties in in vitro and in vivo studies.

\section{Metal Nanoparticles}

Metal NPs present unusual optical, thermal, and physicochemical properties related to the large proportion of high-energy surface atoms compared to their bulk solid [12-15]. These NPs are versatile agents with various applications in biomedicine, including diagnostic assays [16, 17], thermal ablation, efficacy enhancement of radiotherapy [18-21], and drug or gene delivery [22-26].

Depending on the size and composition, metal NPs can represent special properties, such as quantum confinement in semiconductor nanocrystals, surface

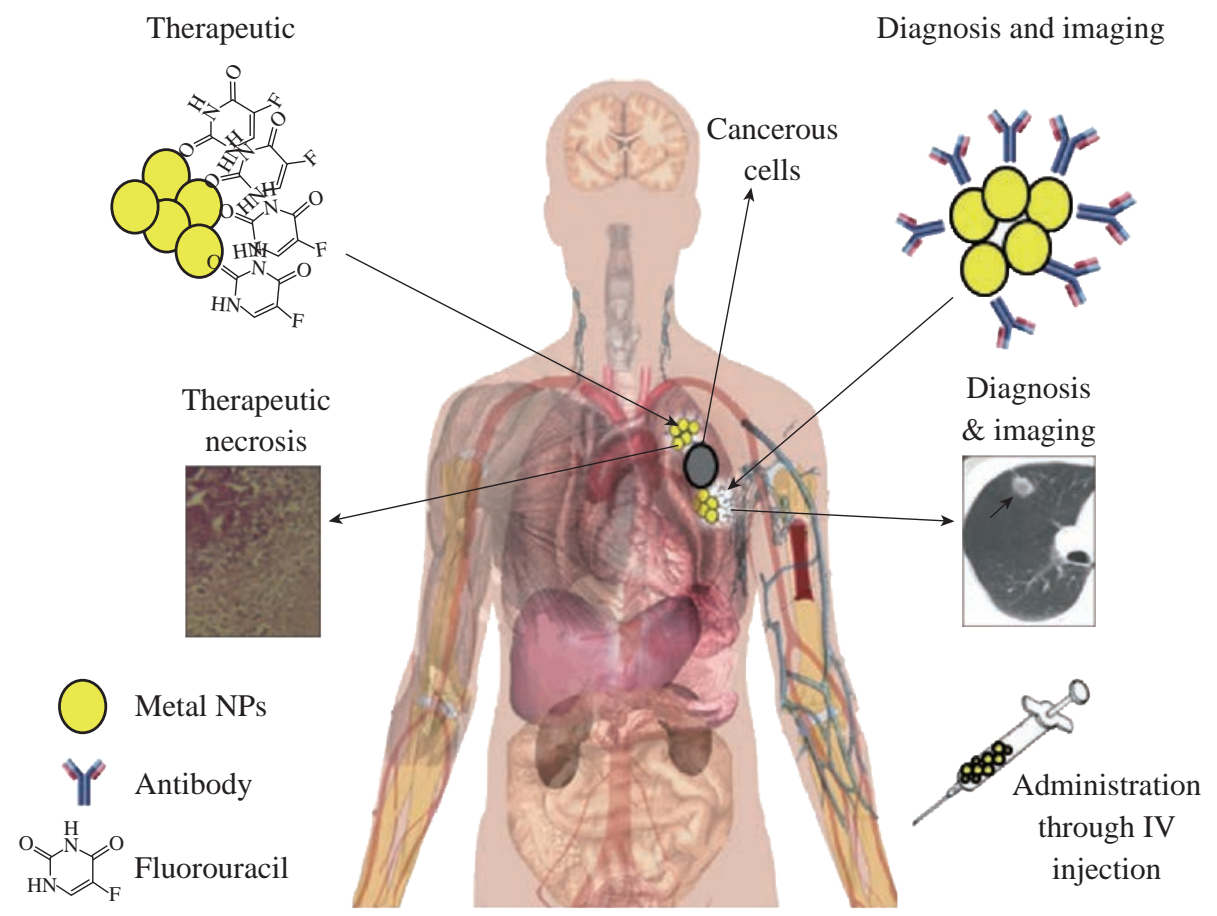

Fig. 1 Diagnostic and therapeutic use of metal NPs. A monoclonal antibody against the cancer cell antigen can be attached to the surface of metal NPs and orient the NPs after intravenous injection to the tumor site and improve the diagnostic results. In therapeutic use, any anticancer drug such as fluorouracil can be loaded on the surface of metal NPs and target the tumor cells. 
plasmon resonance, especially in gold NPs, and superparamagnetism, which is mostly observed in iron oxide NPs $[12,17]$. In the last decade, many dextrancoated magnetic nanoparticle formulations have been approved for clinical use as magnetic resonance imaging (MRI) contrast agents, including ferumoxides, ferumoxtran, and ferucarbotran [27]. Recent advancements also demonstrated that magnetic NPs can be applied for hyperthermic treatment of cancers [28].

Other characteristics of metal NPs such as high surface-to-volume ratio, vast optical properties, simple synthesis, low toxicity, facile surface chemistry and biofunctionalization, and high capacity for carrying therapeutic agents, have led to applications in the clinical field for diagnostic and therapeutic purposes [8, 29, 30]. As mentioned (bio-functionalization), these NPs can easily be functionalized with antibodies, peptides, and/or DNA/RNA for defined target cells [31]. For example, the surface of gold (Au) NPs has a strong binding affinity for thiols, disulfides, and amines [32, 33], a property limited to metal NPs, and the simple Au-thiol chemistry enables the surface conjugation of various peptides, proteins, and DNA [34]. Metal NPs combine with biocompatible polymers (e.g., polyethylene glycol or chitosan), which can extend their in vivo circulation as a carrier for drug and gene delivery [35, 36]. Moreover, metal NPs can convert light or radiofrequencies into heat, which causes thermal ablation of the targeted cancer cells [37, 38]. In this regard, the ability of Au NPs to convert absorbed light proficiently into localized heat can be applied for selective photothermal therapy for cancer [21, 22] or bacterial infection.

In addition, the matchless physicochemical properties of metals at the nanoscale aid the development of wide-spectrum biosensors and other nanotechnology-based tools that help scientific research in basic biology [39-41]. Optical, acoustic wave, electrochemical, and magnetic biosensors are among the nanoparticle-based tools to which many advances in recent years in basic biology have been attributed [42].

\section{Metalloid Nanoparticles}

Metalloids are chemical elements with exclusive characteristics that are in between or a mixture of metals and nonmetals. Therefore, metalloids are difficult to classify as either metal or nonmetal. There is neither a standard definition of a metalloid nor agreement according to which these elements are correctly classified. Metalloids feature metals and nonmetals, and accordingly are known as semimetals [43]. They react with metals like nonmetals and act like metals when they react with non-metals. Metalloid compounds have various biological effects on cells and tissues, and the potential for therapeutic use has grown over the centuries, beginning with the empiric use of arsenic for syphilis treatment before the discovery of antibiotics to the current Food and Drug Administration (FDA) approval of $\mathrm{As}_{2} \mathrm{O}_{3}$ as a drug for treating acute promyelocytic leukemia in humans. Arsenic is a metalloid or semimetal in two biologically important oxidation states, As (III) and As (V), and the role of arsenic as a carcinogen and/or therapeutic agent has remained a dialectical issue [44].

Although the potential of some metalloid compounds as a drug is still ambiguous, the evidence for applying these agents in therapeutic systems is promising. For instance, antimony has been successfully used as a therapeutic agent for treating two parasitic diseases, leishmaniasis and schistosomiasis [45].

Tellurium (IV) is another metalloid, which affects thiol redox biological activity. The formation of a Te (IV)-thiol chemical bond or the formation of a disulfide bond in a specific protein results in conformational change, and may possibly cause the loss of protein biological activity, for example, the inactivation of cysteine proteases in the human body [46]. Silicon dioxide $\left(\mathrm{SiO}_{2}\right)$ similar to iron oxide has been used as a carrier for targeted delivery of drugs and genes [47]. Boron NPs are also an anticancer drug and applied for neutron capture therapy (NCT) [48].

Metalloid NPs have been used for diagnostic assays as well; cadmium telluride NPs and polymercoated bismuth sulfide NPs $\left(\mathrm{Bi}_{2} \mathrm{~S}_{3}\right)$ are being exploited as quantum dots for in vivo imaging and computed tomography (CT). Compared to conventional iodinated imaging agents for CT diagnosis assays, excellent stability at high concentrations, high X-ray absorption (fivefold better than iodine), longer circulation times (>2 h) in vivo, and an efficacy/safety profile make polymer-coated bismuth sulfide NPs a better choice [49].

\section{Methods Used for the Synthesis of Nanoparticles}

There is a vast variety of methods for preparing NPs ranging from synthesis in water, gel templating, and solvent-free methods such as chemical vapor 
deposition (CVD) to electrical explosion and mechanical milling, etc. However, in general, these methods can be categorized into three types of chemical, physical, and biological systems. Through this wide range of methods, some of the chemical and biological (biogenic) syntheses of NPs are reviewed here.

\section{Chemical synthesis}

Many chemical procedures have been investigated for generating inorganic nanomaterials. Chemical reduction of metal salt precursors, electrochemical synthesis, and controlled decomposition of organometallic compounds and metal-surfactant complexes are examples of these methods [50].

Surfactants are frequently used as protective agents or phase transfer agents in chemical synthesis. Borohydride, hydrazine hydrate, and sodium citrate are among the chemicals commonly applied as reducing agents [51].

NPs produced by colloidal chemistry in liquid environments have many roles in many natural, industrial, and biological processes. Typical colloids are representative of NPs stabilized in solution to prevent aggregation. The synthesis of noble metals NPs in organic solvents, including transition metals, oxides, and semiconducting materials, has been widely documented [52, 53].

Some characteristics of NPs such as production rate and crystal structure depend on the environment and are regulated by the ligands' molecules. In this regard, in the absence of ligands, nanoparticle surfaces are in maximum exposure condition, and can easily be accumulated, which results in their precipitation [54]. Water-soluble NPs may be fabricated in one-step inorganic solvents using the wise option of stabilizing agents as amphiphilic ligands such as peptides.

The seed-mediated method is another method of nanoparticle chemical synthesis, which establishes controllable nucleation in addition to the growth of NPs and nanorods in contrast to electrochemical and photochemical methods [55]. Although the CVD method also leads to the production of metal NPs through a chemical method, the resulting NPs have mostly been used in heterogeneous catalysis, magnetic data storage, and nanoelectronic devices rather than biomedicine [54].

Wet chemical methods have been also used to produce various types of nanomaterials with size ranges of $12-50 \mathrm{~nm}$. For instance, the sol-gel technique is a wet chemical method that produces micro- and nanocrystalline powders. The different sol-gel methods are applicable for the production of a wide variety of materials, including nanocrystalline powders, thin films, ceramics, and metal oxide and organic-inorganic hybrid NPs [51].

\section{Biogenic synthesis}

Chemical methods for preparing metal NPs are tedious and expensive, and using capping or stabilizing agents (toxic solvents) in this procedure is unavoidable; however, biogenic synthesis of NPs can overcome these issues [51]. Although many chemical and physical methods are still being used to produce inorganic nanomaterials, the shape and size of the NPs created using these methods cannot be controlled, which is important since size and shape affect NPs' physical, chemical, electronic, and biological properties $[56,57]$.

Several biogenic synthesis processes known for cost-effective and eco-friendly properties have been reported [58]. Microbial systems can detoxify metallic ions through different methods, such as oxidation and reduction of metals [59] (Fig. 2), accumulation of metallic NPs outside the plasma membrane in some bacteria [60], binding of metal ions to peptides (e.g., phytochelatin) to prevent DNA damage [61], use of efflux pump systems [62], precipitation and the creation of carbonates, phosphates, and sulfides metal forms, and metal ion volatilization by methylation and/ or ethylation [63]. The biogenic system is not limited to using bacteria, actinomycetes, fungi, and yeasts to produce NPs; instead, plant or algae extracts and even informational biomacromolecules, including proteins, polypeptides, DNA, and RNA (as other sources of biological materials), can also be applied to produce NPs [51]. For example, informational biomolecules (DNA and RNA) can be applied as building blocks capable of potentially supplying a set of chemical functional groups (e.g., phosphate backbones) that hinder the size and shape control of biomineralized nanomaterials [64, 65].

However, biogenic synthesis has its own drawbacks. For example, since the reduction process may occur extracellularly and/or intracellularly [66], in intracellular production of nanomaterials by microorganisms at the final step, the difficult extraction 

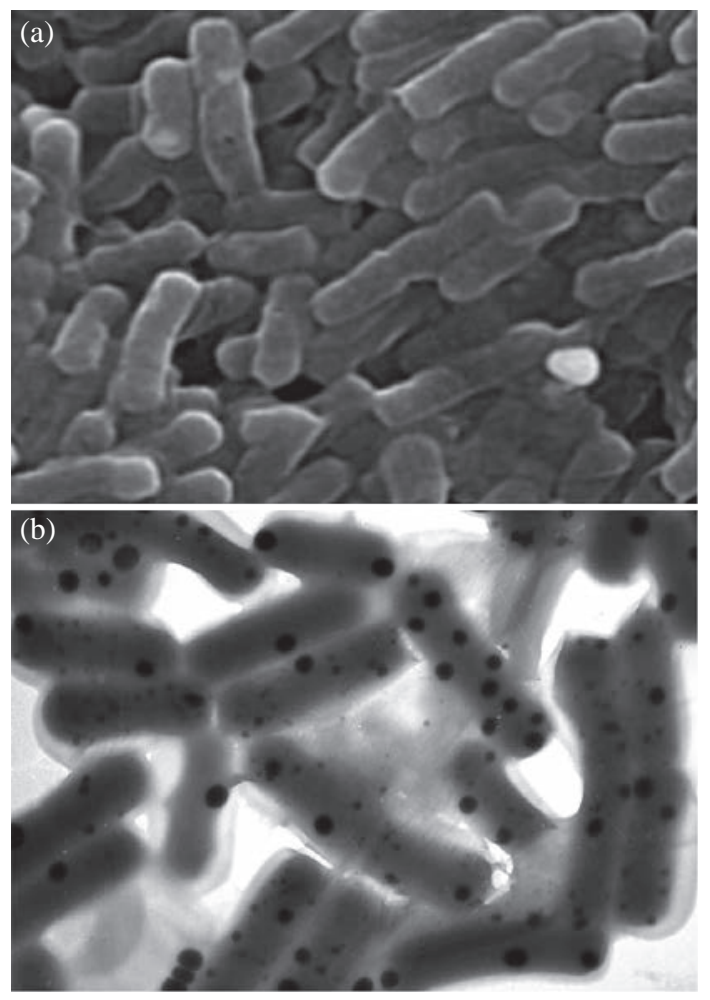

Fig. 2 Biogenic selenium NPs in the intracellular space of Lactobacillus bervis. The scanning electron microscope micrograph of L . bervis (a) without SeNPs and (b) SeNPs in the intracellular space, which are defined as black spots.

procedure is a disadvantage of the biogenic system. In addition, maintaining optimized growth conditions for microorganisms and the production of corresponding biomass for nanoparticle production are other concerns.

In sum, using a viable option for producing nanomaterials depends on many factors, including an assessment of the risks/benefits and available condition.

\section{Metal Nanoparticles and Cancer}

Among the characteristics of metal NPs, such as high surface-to-volume ratio and simple synthesis procedure, some traits such as easy surface chemistry or biofunctionalization and vast optical features have a key role in bringing these NPs to the clinic in cancer therapy and diagnosis [8, 30]. Metal and metal oxide NPs such as gold, silver, and iron oxide (Table 1) are of much interest in cancer research (67-92). Therefore, in the following, the application of these NPs in cancer science is reviewed.

\section{Gold nanoparticles}

Gold compounds have been classically used in medicine for various purposes such as vital power and curing male impotency [93, 94]. Epilepsy, syphilis, rheumatic disorder, tuberculosis, and different skin diseases were also cured by ancient gold [95, 96]. Gold NPs (Au NPs) have tunable optical properties based on the size and shape of the particles that make them promising and unique contrast agents for biomedical imaging [97]. Like other metal NPs, Au NPs have the ability to conjugate with a wide range of biological ligands such as oligonucleotides (DNA, RNA), peptides, proteins, viruses, and receptors through the thiol, disulfide, phosphine, or amine functional groups (Fig. 3) [98]. Numerous studies have implied Au NPs have a role in cancer diagnosis and therapy.

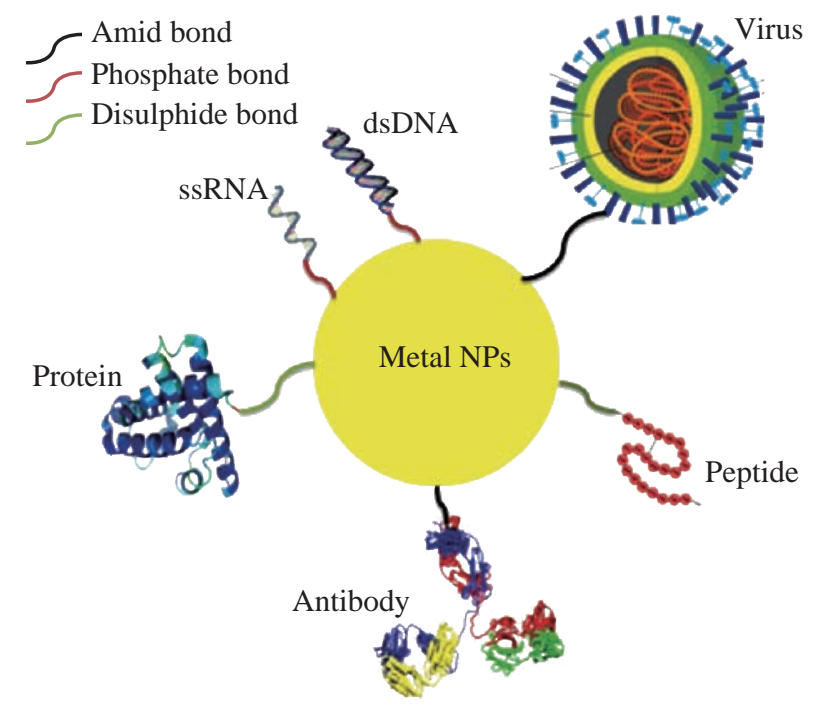

Fig. 3 Biomolecules can be loaded on the surface of metal NPs. Metal NPs have easy surface chemistry, and a wide range of biomolecules can be loaded on the surface of these NPs using amine, phosphate, and disulphide bonds. This property, called biofunctionalization, holds much interest for using metal NPs for different biomedical applications.

Choosing a treatment strategy for patients with cancer depends on various factors, including the type of tumor and the stage of the disease [99]. Chemotherapy and radiation, known as routine therapeutic modalities for cancer, have some nonspecific cell damage that limits their application. Photothermal therapy is also controversial due to its side effects on surrounding cells [100]. In fact, undifferentiated heating of normal and tumor cells in photothermal therapy is a big limiting factor and requires a logical design for tumor targeting and regulated delivery. Au NPs can be used as a probe for guiding the heat into the targeted cells. Compared to commonly used materials, such as indocyanine green, which have been applied for laser photothermal 
Table 1 Metal and metal oxide nanoparticles and cancer research

\begin{tabular}{|c|c|c|c|c|}
\hline Metal NPs & Type of Cancer & $\begin{array}{l}\text { Used as Diagnostic (D) } \\
\text { or Therapeutic }(\mathrm{T})\end{array}$ & Consequence & Reference \\
\hline \multirow[t]{9}{*}{ Au NPs } & Cervical Cancer & Real-time vital optical imaging (D) & Allow mass screening of cancer & 1,2 \\
\hline & Epithelial carcinoma & Laser photo-thermal therapy (T) & $\begin{array}{l}\text { Selective photothermal therapy with } \\
\text { molecular cancer cell targeting }\end{array}$ & 3 \\
\hline & Murine breast cancer & Positron emission tomography (PET) (D) & $\begin{array}{l}\text { Rapid accumulation and retention of } \mathrm{Au} \\
\text { nanocages inside the tumors }\end{array}$ & 4 \\
\hline & Human Cancer Cells & $\begin{array}{l}\text { Hyperthermia with near-infrared laser } \\
\text { irradiation }(\mathrm{T})\end{array}$ & $\begin{array}{l}\text { Possibility of using adenoviral vectors as } \\
\text { carriers for gold nanoparticles }\end{array}$ & 5 \\
\hline & Human nasal epithelial cell carcinoma & Induction of apoptosis (T) & $\begin{array}{l}\text { AuNPs is cytotoxic to NPC cells at high } \\
\text { concentrations }\end{array}$ & 6 \\
\hline & Human cervical cancer cell line & Combination therapy (T) & $\begin{array}{l}\text { Photothermal therapy along AuNPs and } \\
\text { 5-aminolevulinic acid induced ROS } \\
\text { dependent apoptosis }\end{array}$ & 7 \\
\hline & Human fibroblastoma cells & Anti-metastatic activity (T) & $\begin{array}{l}\text { AuNPs inhibit the chemo-attractant cell } \\
\text { migration of human fibrosarcoma cancer } \\
\text { cell }\end{array}$ & 8 \\
\hline & Human solid tumor & As radiosensitizer in radiotherapy $(\mathrm{T})$ & $\begin{array}{l}\text { combined benefit of anti-angiogenic and } \\
\text { cytotoxic dose enhancement effects }\end{array}$ & 9 \\
\hline & Human cancer & $\begin{array}{l}\text { Imaging and the detection of cancer cells } \\
\text { (D) }\end{array}$ & $\begin{array}{l}\text { Ultrasensitive detection of cancer cells } \\
\text { when } \mathrm{Au} \text { is combined with } \mathrm{Fe}_{3} \mathrm{O}_{4}\end{array}$ & 10 \\
\hline \multirow[t]{10}{*}{ Ag NPs } & Human lung cancer cells & $\begin{array}{l}\text { As a therapeutic agent to induce cell } \\
\text { death }(\mathrm{T})\end{array}$ & $\begin{array}{l}\text { Increased lipid proxidation and decreased } \\
\text { glutathione (GSH) levels }\end{array}$ & 11 \\
\hline & $\begin{array}{l}\text { Human dermal fibroblast (HDF) } \\
\text { Lung cancer (A549) cells }\end{array}$ & $\begin{array}{l}\text { Modified surface of Ag NPs used as } \\
\text { therapeutic agent }(\mathrm{T})\end{array}$ & $\begin{array}{l}\text { Ag NPs induced necrosis and apoptosis } \\
\text { in both cell types }\end{array}$ & 12 \\
\hline & Mouse fibroblast cell lines $3 \mathrm{~T} 3$ & X-ray irradiation $(\mathrm{T})$ & $\begin{array}{l}\text { Ag NPs is a good candidate forcancer } \\
\text { radiation therapy }\end{array}$ & 13 \\
\hline & Human oral squamous carcinoma & $\begin{array}{l}\text { As a agent to induce programmed cell } \\
\text { death }(\mathrm{T})\end{array}$ & $\begin{array}{l}\text { Ag NPs lead to engulfment of apoptotic } \\
\text { cancer cells by neighboring cells }\end{array}$ & 14 \\
\hline & $\begin{array}{l}\text { Human non-small lung cancer cells } \\
\text { (NCI-H460). }\end{array}$ & As a photothermal therapy agent $(\mathrm{T})$ & $\begin{array}{l}\text { Ag NPs as effective phototherapeutic } \\
\text { agents when are coated with chitozan }\end{array}$ & 15 \\
\hline & Glioma cells & Hyperthermal therapy (T) & $\begin{array}{l}\text { Ag NPs enhanced thermo-sensitivity of } \\
\text { glioma cells and induced G2 arrest }\end{array}$ & 16 \\
\hline & Human colon cancer cells (HT 29) & $\begin{array}{l}\text { Induction of ROS dependent apoptosis } \\
\text { (T) }\end{array}$ & $\begin{array}{l}\text { Lower concentration of Ag NPs } \\
\text { impregnated in chitosan nanocarrier } \\
\text { needed for induction of apoptosis }\end{array}$ & 17 \\
\hline & Human prostat cancer & Electrochemical immunosensor (D) & $\begin{array}{l}\text { Ag NPs allow to detect PSA biomarker } \\
\text { over a wide concentration range }\end{array}$ & 18 \\
\hline & Glioblastoma cell lines & Inducing cytotoxic effect (T) & $\begin{array}{l}\text { The uptake of Ag into the cells has } \\
\text { quantified and an interesting cytotoxic } \\
\text { effect }\end{array}$ & 19 \\
\hline & $\begin{array}{l}\text { Tamoxifen-resistant T47D } \\
\text { cells (breast cancer) }\end{array}$ & Cancer chemotherapy (T) & $\begin{array}{l}\text { Ag NPs has a great potential in } \\
\text { chemotherapy of breast cancer }\end{array}$ & 20 \\
\hline \multirow[t]{6}{*}{$\begin{array}{l}\text { Iron oxide } \\
\text { NPs }\end{array}$} & MDA-MB-231 breast cancer cells & $\begin{array}{l}\text { Cell tracking with magnetic resonance } \\
\text { imaging (MRI) (D) }\end{array}$ & $\begin{array}{l}\text { Iron oxide NPS leads to better monitoring } \\
\text { of breast cancer cells' proliferation }\end{array}$ & 21 \\
\hline & T47D breast cancer cell line & Thermal ablation (T) & $\begin{array}{l}\text { Iron oxide NPs cause cell necrosis by } \\
\text { heating antibody functionalized metallic } \\
\text { nanoparticles attached to cancer cells }\end{array}$ & 22 \\
\hline & $\begin{array}{l}\text { M059K (glioblastoma), MDA MB } \\
231 \text { (breast carcinoma), and A549 } \\
\text { (lung adenocarcinoma) }\end{array}$ & $\begin{array}{l}\text { Hyperthermia in conjunction with } \\
\text { irradiation and/or chemotherapy }(\mathrm{T})\end{array}$ & $\begin{array}{l}\text { The efficacy of paclitaxel was greater } \\
\text { with hyperthermia for the A549 cells; } \\
\text { however, the M059K and MDA MB } 231 \\
\text { did not show the same response }\end{array}$ & 23 \\
\hline & KB cancer cells & $\begin{array}{l}\text { Hyperthermia by alternating magnetic } \\
\text { field and controlled drug release }(\mathrm{T})\end{array}$ & $\begin{array}{l}\text { AMF triggered distance-dependent } \\
\text { release of the drug with azo- } \\
\text { functionalized iron oxide NPs }\end{array}$ & 24 \\
\hline & Human breast cancer cell (MCF-7) & $\begin{array}{l}\text { Hyperthermic adjuvant chemotherapy or } \\
\text { thermochemotherapy }(\mathrm{T})\end{array}$ & $\begin{array}{l}\text { Thermochemotherapy combined } \\
\text { with methotrexate can realize cancer } \\
\text { comprehensive treatment and has great } \\
\text { potential in clinical application }\end{array}$ & 25 \\
\hline & Mouse multiple myeloma cell line & $\begin{array}{l}\text { Combining Magnetic Resonance Imaging } \\
\text { and Hyperthermia Treatment (D, T) }\end{array}$ & $\begin{array}{l}\text { Iron oxide NPs modification with } \\
\text { PEG and folic acid resulted in better } \\
\text { accumulation in tumor and better } \\
\text { treatment prognosis }\end{array}$ & 26 \\
\hline
\end{tabular}


therapy, Au NPs demonstrated much lower irradiation energy needed for killing tumor cells [97].

The ability of Au NPs to provide a stable milieu for biomolecules or easy bioconjugation of Au NPs with different types of ligands has led to tremendous interest in using these agents for targeting tumor therapy [101, 102]. Huang et al. [22] used Au NPs conjugated to anti-epidermal growth factor receptor (EGFR) antibody with near infrared (NIR) scattering for selective photothermal damage to cancer cells. Au NPs were also used to conjugate with antibody against human epidermal growth factor receptor (HER-2), which is overexpressed in breast cancer to enhance detection of this cancer with X-ray radiography [103].

Bhattacharya et al. [96] have shown that Au NPs have anti-angiogenic and anti-tumor properties and can be applied as an active agent for cancer therapy. Selective delivery of Au NPs to the tumor site is crucial for therapeutic application. Since many solid tumors have a disorganized and highly permeable vascular network, intravascular injection of Au NPs seems an attractive method for affecting more tumor cells [104]. Extravasation from the blood circulation into solid tumors causes the accumulation of many NPs with a size range of $60-400 \mathrm{~nm}$. To minimize the agglomeration, extend blood circulation time, and mask NPs from the immune system, it is better to cover them up with biocompatible polymers such as polyethylene glycol (PEG). O'Neal et al. [105] showed that injecting PEG-coated nanoshells through the tail vein of mice resulted in preferential accumulation of these agents in the tumor region in the first $6 \mathrm{hrs}$.

Early detection of cancer by monitoring biomarkers is crucial to safeguard the fate of the therapeutic intervention. Since tumor cells assimilate many molecular changes compared to normal cells, targeting these changes via nanoconjugated tools helps the diagnostic system in terms of specificity and sensitivity. Colloidal Au NPs have a strong surface plasmon resonance (SPR) absorption and scattering ability, which makes them an important tool for a diagnostic system as a contrast agent $[106,107]$.

Binding antibody conjugated NPs to cancer cell surface molecules causes sharper SPR absorption bands and demonstrated six times greater affinity compared to the attachment of these agents to noncancerous cells [106]. Moreover, the intensity assessment of the absorption band in cancerous and non-cancerous cells indirectly indicate the over-expression of target molecules in cancer cells [106]. This technique is effective for detecting precancerous cells by changing the target molecule. In addition, multicolor imaging of different targets can be attained with a single white light source using Au NPs in different sizes and shapes conjugated to different molecules as probes and resulting in more precise detection of the cancer stage [104]. Immunogold NPs have also been used since the 1980s with conjugation of a fragment of antibody binding (Fab) for biological labeling and staining in the electron microscopy technique [108]. Based on these properties, Au NPs are an important part of the progress in biological science.

\section{Silver nanoparticles}

The biomedical application of silver compounds mostly depends on antibacterial properties and for external infections in which silver is applied in wound dressings, creams or ointments, and catheters and as an antibiotic coating agent on medical devices. Silver NPs (Ag NPs) are used similarly in biomedicine due to their antibacterial or antifungal properties [109], although exposure to silver NPs has been associated with many health concerns such as inflammatory responses, oxidative stress, and cell cytotoxicity [110]. However, potential toxicity, tissue distribution, and cellular uptake of silver NPs have previously been studied, and the results showed that silver NPs mainly accumulate in the liver and are a toxic agent for other organs such as the brain [111]. Daniel et al. [112] also reported that starch or BSA stabilized silver NPs can induce clear developmental defects in zebrafish embryos that may activate health-related concerns. Therefore, the risk of biomedical application of Ag NPs remains controversial and not entirely known since few reports on the toxicity of silver NPs are available, and in contrast to the data, the results of several animal studies demonstrated that silver NPs are not toxic and showed no immune response [113]. Likewise, even if all concerns about silver toxicity are confirmed, the biological synthesis of silver NPs can minimize their toxicity, and the resulting NPs are remarkably more stable [114]. Recently, silver NPs have been tested as anticancer agents. Jeyaraj et al. [115] have shown that biogenic Ag NPs achieved by using Sesbania grandiflora leaf extract as a novel reducing agent have a cytotoxic effect against human breast cancer (MCF-7) cell lines. Ag NPs combined with lanthanum magnetite particles are also an ideal tool for inducing hyperthermia (TC $41-44{ }^{\circ} \mathrm{C}$ ) 
[116]. Using starch-coated silver NPs have shown an antimitotic effect on human glioblastoma cells (U2510) and human lung fibroblast cells (IMR-90). Ag NPs affect these cancer cells through ATP depletion, mitochondrial damage, cell cycle arrest in the G2/M phase in addition to enhancement of reactive oxygen species (ROS) generation [117]. The cell titer blue viability assay confirms mitochondrial damage in the presence of silver NPs. Mitochondrial dysfunction results from ROS production and subsequent oxidative stress, which is a common mechanism for the cell damage induced by nanomaterials [118]. The presence of silver NPs in the brain has been previously shown [119]. The ability of nanosilver to penetrate the bloodbrain barrier without producing apparent toxicity may cause optimism for targeting brain tumors with drug-conjugated nanosilver. For tumor imaging and diagnostic systems, silver exhibits stronger and sharper plasmon resonance peaks than gold; therefore, Ag NPs were chosen. The chemical properties of colloidal silver make it a promising candidate for targeted drugs or a gene delivery approach to specific cells [120]. Wu et al. [121] used silver NPs as a platform for drug delivery. Silver NPs have a wide range of surface functional groups by which multiple diagnostic and therapeutic agents can be conjugated.

Many researchers have attempted to functionalize silver NPs with bioreceptors (BSA) for biosensing applications. Once proteins bind to silver NPs, the intensity and the wavelength of the particles are changed; therefore, using silver NPs coated with a protein or antibody is a promising approach as an alternative for ordinary biosensing techniques [122].

A major goal of nanomedicine in oncology is to use a molecule to offer the opportunity for simultaneous targeting, imaging, and treatment. In this regard, multifunctional nanostructures composed of silver can be used as a tool for diagnostic and therapeutic systems. However, despite the beneficial properties of silver NPs, due to health and environmental safety concerns, silver NPs have still a long way to go to be confirmed in clinical trials.

\section{Iron oxide nanoparticles}

Iron oxide is the main component of magnetic NPs. Iron oxide NPs have attracted much interest based on their superparamagnetic properties and their potential applications in many fields. Thermal energy, quantum size effects, and large surface area of iron oxide, are responsible for this super-paramagnetic property [123]. Some factors such as low toxicity and the known metabolism pathways make superparamagnetic iron oxide NPs (SPIONs) interesting tools in biomedicine [124]. Iron oxide NPs not only have been used as high-sensitive biomolecular magnetic resonance imaging (MRI) agents in diagnostic system but also may be useful tools for tissue repair, detoxification of biological fluids, immunoassay, hyperthermia, drug delivery, and cell separation [125]. The main forms of iron oxide NPs are magnetite $\left(\mathrm{Fe}_{3} \mathrm{O}_{4}\right)$ and its oxidized form maghemite $\left(\gamma-\mathrm{Fe}_{2} \mathrm{O}_{3}\right)$ or hermatite $\left(\alpha-\mathrm{Fe}_{2} \mathrm{O}_{3}\right)$ particles. Although mixed oxides of iron with transition metal ions such as copper, cobalt, nickel, and manganese also have superparamagnetic properties and are known as SPIONs [126], maghemite and magnetic NPs are the most commonly used SPIONs in various biomedical applications since they are biocompatible and nontoxic for humans [127]. Cobalt (Co) and nickel (Ni) also even more magnetic properties than iron oxide, but they are highly toxic; thus, they are not usually applied in biomedicine. Using SPIONs in oncology is not limited to cancer detection as a contrast agent. Modifications of magnetic NPs make them interesting options for cancer therapeutic systems. Collagen-based magnetic nanobiocomposites have been established as an MRI contrast agent and as a carrier for delivering cancer drugs [128]. Since iron oxide NPs use folate receptors to enter cells, over-expression of this receptor on the surface of cancer cells, as previously demonstrated [129], may be a useful point for an anticancer drug delivery approach using these NPs [130]. In this regard, iron oxide NPs have recently been applied as nanocarriers for docetaxel, an anti-breast and ovarian cancer drug [131]. Various biological molecules such as antibodies, proteins, and targeting ligands may also be attached to the surfaces of iron oxide NPs via amide or ester bonds aiming to deliver SPIONs to specific targets [125].

Several groups of coating agents are used to modify the surface chemistry of iron oxide NPs to extend the time of blood circulation and reduce the immune response, and thus clear them from the body [132]. Likewise, appropriate surface coating lets iron oxide NPs disperse into homogenous ferrofluids and thus improve their stability [133].

Cancer hyperthermia, which means exposing cancer tissues to an alternating magnetic field to raise the cells' temperature, is another application of iron oxide NPs, and a hot iron has been used historically 
for treating surface tumors [134]. Cancer cells are damaged by temperatures higher than $43^{\circ} \mathrm{C}$, whereas normal cells can survive at even higher temperatures. The amount of heat generated is related to the nature of the magnetic material and the magnetic field applied. Magnetic induction hyperthermia can be used along with specific antitumor gene expression such as TNF- $\alpha$ in tumor cells involving an appropriate heat-sensitive promoter like gadd 153 [135] by which a two-edged sword can be simultaneously triggered against cancer development. Cancer hyperthermia with magnetic NPs has also been investigated for its probable effect on inducing apoptosis in cancer cells [136]. In addition, antitumor immune responses induced by hyperthermia using magnetite NPs also help the treatment process [137]. Overall, iron oxide NPs have enough potential to help researchers design new and efficient strategies for early detection of cancer cells and powerful eliminating programs.

\section{Metalloid Nanoparticles and Cancer}

Metalloids have metal and nonmetal features [43]. Boron, silicon, germanium, arsenic, tellurium, and bismuth are commonly known metalloids that have different applications in biomedicine [138-159] (Table 2). In the following section, tellurium is reviewed in more detail based on applications in cancer research [43]. Meanwhile, the application of bismuth NPs will be presented here. Although there is not a lot of data about the application of other metalloid NPs in medicine in cancer research in particular, to the best of the authors' knowledge, boron NPs have been used for different diagnosis or therapeutic purposes in cancer models [160, 161], but other metalloid NPs such as germanium are frequently used in other areas of nanotechnology. Silicon NPs are also well-known as quantum dot (QD) agents and typically used for diagnostic systems [162]. Despite toxicity concerns about arsenic, arsenic trioxide $\left(\mathrm{As}_{2} \mathrm{O}_{3}\right)$ NPs have recently been considered a promising anticancer agent for solid tumors [143, 163].

\section{Tellurium nanoparticles}

Tellurium, a chemical element with symbol Te and located in a chalcogen group of the periodic table, is a brittle, mildly toxic, rare, and silver-white metalloid that looks similar to tin. Based on chemical properties, tellurium is related to selenium and sulfur. Tellurium is occasionally found in elemental or crystal form in its origin and occurs in inorganic and organic compounds [164]. Little is known about tellurium applications in biomedicine. From the past to present, a big concern accompanying the biomedical application of tellurium has been acute and subacute toxicity, which can be observed as a result of inhibition of glutathione peroxidase, bonding with sulfhydryl groups in different molecules, damage to nerves, the liver, and gastrointestinal cells, and disrupting of cholesterol metabolism pathways [165]. In contrast to the tellurium ion, tellurium NPs are gaining interest in biomedicine because they have lower toxicity than ionic tellurium, especially when they are used in combination with other compounds such as silica or cadmium in coated form [166].

The application of tellurium NPs in cancer research varies from diagnostic to therapeutic modalities, in particular as a QD agent $[167,168,150]$. Cadmium is usually combined with tellurium when QDs are applied. For instance, cadmium and tellurium (CdTe) in conjugation with human epidermal growth factor receptor 2 (HER2) monoclonal antibody have been recently used as a safe and effective nanoprobe for targeted imaging and selective therapy of gastric cancer [151]. In addition, CdTe QDs have great potential in treating cancer using photothermal therapy. Similar to many other metalloid NPs, this effect is due to the physical properties of CdTe NPs [150]. The detection of micrometastasis or tumor shedding antigens as cancer biomarkers have a key role in diagnosing early-stage cancer and in monitoring cancer progress. Accordingly, using a new method for screening micrometastasis in peripheral blood samples seems to be valuable for managing cancer patients' treatment protocols.

Tellurium NPs have been used for this purpose and showed great potential, especially when used along with magnetic NPs (MNPs) and QDs [152]. However, despite this evidence, the toxicity of tellurium NPs is not truly understood for the health care system. Therefore, much effort has been made to overcome this problem. As a toxicity-reducing strategy for NPs, biocompatible polymers such chitosan, polyethylene glycol (PEG), or even gelatin and encapsulation of NPs with polymers are safe and easy approaches. Gelatin was previously examined as a coating agent and effectively reduces the cytotoxicity of NPs. Gérard et al. [156] described that coating CdTe QDs with gelatin and targeting this agent with folic acid, which is usually over-expressed in almost all tumor cells, 
Table 2 Metalloid nanoparticles and cancer research

\begin{tabular}{|c|c|c|c|c|}
\hline Metalloid NPs & Type of cancer & Application & Consequence & Reference \\
\hline \multirow[t]{3}{*}{ BNPs } & Breast cancer & Early diagnosis & $\begin{array}{l}\text { As a screening tool to detect smaller breast } \\
\text { cancers before they are detectible by traditional } \\
\text { mammography }\end{array}$ & 27 \\
\hline & $\begin{array}{l}\text { Human lung adenocarcinoma } \\
\text { A549 cells }\end{array}$ & $\begin{array}{l}\text { Boron neutron capture therapy } \\
\text { (BNCT) and photodynamic } \\
\text { therapy (PDT). }\end{array}$ & $\begin{array}{l}\text { Conjugation with a closo-dodecaborate causes } \\
\text { photoinduced cell death }\end{array}$ & 28 \\
\hline & Human Hepatoma HepG2 cells & $\begin{array}{l}\text { Boron neutron capture therapy } \\
\text { (BNCT) }\end{array}$ & $\begin{array}{l}\text { Dendritic glyco-borane, DGB showed ten-fold } \\
\text { improvement in killing the HepG2 cells }\end{array}$ & 29 \\
\hline \multirow[t]{2}{*}{ SiNPs } & $\begin{array}{l}\text { Pancreatic malignant tumor } \\
\text { cells }\end{array}$ & Cancer photothermotherapy & $\begin{array}{l}\text { The DMSO porous silicon colloid in combination } \\
\text { with an NIR laser resulted in a a sufficiently high } \\
\text { cytotoxic effect }\end{array}$ & 30 \\
\hline & Breast cancer cells & Photodynamic therapy & $\begin{array}{l}\text { Non-toxic porous silicon nanoparticles carry } \\
\text { porphyrin covalently attached to their surface } \\
\text { inside breast cancer cells for a more efficient } \\
\text { photodynamic effect }\end{array}$ & 31 \\
\hline \multirow[t]{3}{*}{ AsNPs } & $\begin{array}{l}\text { Human pancreatic cancer cells } \\
\text { PANC-1 }\end{array}$ & $\begin{array}{l}\text { Potential for better therapeutic } \\
\text { efficacy }\end{array}$ & $\begin{array}{l}\text { AsNPs in conjugation with anti-CD } 44 v 6 \text { single chain } \\
\text { antibody in inhibiting tumor growth and } \\
\text { the enhanced cell apoptosis agent }\end{array}$ & 32 \\
\hline & Human breast cancer cell lines & Therapeutic efficacy & $\begin{array}{l}\text { Improvement of As NPs formulation against solid } \\
\text { tumor }\end{array}$ & 33 \\
\hline & $\begin{array}{l}\text { human nasopharyngeal Human } \\
\text { cervix (HeLa) cells, human } \\
\text { breast (MCF-7) tumor cells }\end{array}$ & Anticancer efficacy & $\begin{array}{l}\text { Folate-mediated intracellular drug delivery increases } \\
\text { the anticancer efficacy of } \mathrm{As}(2) \mathrm{O}(3) \text { liposomal } \\
\text { nanoparticulate }\end{array}$ & 34 \\
\hline
\end{tabular}

$\begin{array}{ll}\text { Xenograft human } & \text { Radiofrequency-induced } \\ \text { hepatocarcinoma } & \text { hyperthermia }\end{array}$

BiNPs

Mouse hepatoma H22 cells

Circulating tumor cells (CTCs) Detection and killing of CTCs with X-ray radiation

Mouse breast cancer (4T1)

Cells

X-ray computed tomography imaging

TeNPs

Mouse melanoma tumors

Gastric cancer

Lung cancer

Photothermal cancer therapy

Targeted imaging and selective therapy

Chronic myelogenous leukemia Electrochemical DNA biosensor (CML)

Prostate cancer

Breast Cancer cells

Colon cancer Caco-2 cell

Melanoma

HeLa contaminant KB cells

HepG2 and HeLa cancerous cells

Detection of micrometastases in early-stage of cancer with QDs for detection of chronic myelogenous leukemia (CML)

Detection of prostate protein antigen (PSA)

Detection of the expression of HER2

In vitro cancer diagnosis

Therapeutic for cancer stem cells

Photodynamic therapy (PDT)

$\mathrm{As}(2) \mathrm{O}(3) / \mathrm{Fe}(2) \mathrm{O}(3)$ complexes exerted

radiofrequency-induced hyperthermia and drug toxicity on tumors without any liver or kidney damage

Localized and irreversible photothermal ablation of tumors in the mouse model is successfully achieved by using $\mathrm{Bi}_{2} \mathrm{Se}_{3}$ nanoplates and NIR laser irradiation

The dose of primary X-rays can be enhanced to kill the localized CTCs by radiation induced DNA damage, with minimal invasiveness

Monodispersed $\mathrm{Bi}_{2} \mathrm{~S}_{3} \mathrm{NPs}$ yield sufficient contrast to provide quantitative, high fidelity CT images of tumors for1 week postinjection.

CdTe NPs have a great potential in the treatment of cancer using photothermal therapy.

High-performance HER2-RQDs nanoprobes exhibit great potential in applications such as in-situ gastric cancer targeted imaging, and selective therapy

Out of 26 cases with the enriched circulating tumor cells (CTCs), 21 cases were successfully identified by QDs.

Nanostructured composite of chitosan (CS)-cadmium- 42 telluride quantum dots can be used to distinguish CML positive and the negative control samples

Using CdS-TiO(2) nanotube is of great promise in clinical screening of cancer biomarkers like PSA

$\mathrm{CdTe} / \mathrm{ZnSe}$ core/shell quantum dots is a good

fluorescence probe in breast cancer cells

The modification with folic acid caused gelatinecoated CdTe quantum dots to be as good candidate for in vitro cancer diagnostics

36

38

Treatment of melanoma cells with CdTe QDs results 46 in an increase of stem-like cell subpopulations

CdTe(S)-type QDs led to an enhanced photocytotoxicity response

Hybrid material with enhanced photodynamic properties
CdTe nanocrystals caused the improvement in the cell 48 kill efficiency of the methylene blue 
showed great potential for in vitro cancer diagnosis.

Although the many biological roles of tellurium have not been clearly established, the immunomodulatory effect of this metalloid has been acknowledged [169]. Thus, in addition to the many direct effects of tellurium NPs on combatting cancer, this indirect role, potentiating the immune response and reinforcing immune cells, could also be beneficial in inhibiting cancer development. AS101, a small tellurium IV compound, is now in phase II clinical trials in patients with cancer, and represents a potent immunomodulator with various potential therapeutic applications [170, 171]. AS101 also interacted with thiols, which inhibited the activity of specific proteins, in which the redox status of cysteine is essential for their biological activity [169].

One of the most important among these proteins is integrins, which have a role in the attachment of cells to the extracellular matrix [172]. Accordingly, any change in the activity of this protein results in inhibition of metastasis, a crucial step for any malignant tumor. We also observed evidence of this change in malignant cells treated with tellurium NPs. Considering these findings and based on the history of selenium application in medicine, doubtfully used primarily, and the relatedness of tellurium and selenium in many traits, tellurium and in particular tellurium NPs could probably open a new window in cancer treatment and diagnosis protocols.

\section{Bismuth nanoparticles}

Bismuth is a metalloid element with symbol $\mathrm{Bi}$ and atomic number 83. In oncology, bismuth in the form of the 213 radioisotope has been administered for alpha radiation treatment of melanoma, breast, prostate, and colorectal cancers [173]. For diagnostic $\mathrm{X}$-ray sources, bismuth NPs provide higher dose enhancements than gold and platinum NPs for a given nanoparticle size, concentration, and location [174]. We have recently shown the antibacterial effect of biogenic bismuth NPs against Helicobacter pylori [175]. Since H. pylori infection is a major risk factor for developing stomach cancer, this agent can be entered in experimental studies as a cancer prevention strategy using metalloid NPs. Bismuth NPs have also been used for computed tomography (CT) scans in diagnosis tests. Safety tests showed that bismuth NPs with a LyP-1 molecule as a tumor-targeting antigen were well-tolerated when they were injected into mice, and the NPs were cleared from the blood and accumulated in tumors within $24 \mathrm{hrs}$ [149].

\section{Selenium Nanoparticles}

Selenium (Se) is an important micronutrient ion with many biological benefits, including antioxidant effects, cancer prevention, and antiviral activities [176]. Generally, two types of selenium supplements are available; the first type is the salt form of selenium such as sodium selenite or selenate and selenium dioxide. The other type of selenium (called organoselenium) includes selenocysteine and selenomethionine. Selenium yeast, produced by fermenting Saccharomyces cerevisiae in a seleniumrich medium, is also a recognized source of organic food-form selenium [177]. Different types of selenium may act differently in the human body when consumed [178]. The biological effects of Se mostly depend on the incorporation of this metalloid into selenoproteins in the form of the amino acid selenocysteine [179].

In fact, selenocysteine (SeCys) has its own codon in mRNA that specifies its insertion in selenoproteins. Selenoproteins have a major role in maintaining redox balance, but unfortunately, other functions mostly remain unrealized [180]. However, one other effect of selenoproteins in human health is related to their corporation in immune responses and body defense against foreign substances or malignancies [181].

Although many past and ongoing clinical trials are trying to use selenium as a chemopreventive agent to control the incidence of cancers, the trials have had controversial results and even denied the preventive role of this micronutrient [178]. Unfortunately, in spite of all available data, the therapeutic effects of selenium are not fully understood in cancer patients. In particular, consuming selenium in a therapeutic regime in addition to conventional anticancer treatments seems more efficient due to the immunostimulatory effect of this element. However, similar to many other trace elements, a big concern limiting selenium application is the toxicity of this element close to its effective dose.

Elemental selenium at the $\mathrm{Se}^{0}$ state known as nanoselenium is an insoluble metalloid compound that can be synthesized chemically or biologically at nanoscale [182]. Elemental Se has various allotropic forms, including a red amorphous form, a black vitreous form, three $(\alpha, \beta, \gamma)$ red crystalline monoclinic forms, and a grey/black crystalline hexagonal form, 
which is the most stable [183]. Since the toxicity reported for elemental nanoselenium $\left(\mathrm{Se}^{0}\right)$ is lower than that for selenate $\left(\mathrm{Se}^{+2}\right)$ or selenite $\left(\mathrm{Se}^{+4}\right)$ ions, Se nanoparticle can be considered as a good candidate to replace selenium in clinical practice [184]. In the past decade, Se NPs were highly research friendly due to the similarity of biological properties to Se ions even in lower doses with lower toxicity [185].

\section{Anticancer effect of Se nanoparticles}

In cancer treatment and diagnosis, Se NPs have attracted researchers' attention and were used in different studies [186-202] (Table 3). Se NPs can be prepared chemically and biologically. Recently, biological methods for producing Se NPs by bacteria such as Bacillus and Lactobacillus species have been optimized in our laboratory [203, 189]. We applied these biogenic NPs to trigger the immune response of cancer-bearing animals and indirectly inhibited tumor development [191]. The purpose of selecting biogenic Se NPs instead of chemically produced peers was related to the feature of functional groups on the surface of NPs. In biogenic Se NPs, different functional groups are present, which refer to the source and milieu of production. One of the most likely components accompanying biogenic Se NPs is bacterial antigens, which in our experiments belonged to Lactobacillus species. Lactic acid bacteria are known safe for human and animal consumption and have been used as probiotics. However, the immunomodulatory effect of these bacteria is interesting and has been previously studied [204, 205]. In addition, Lactobacilli enriched with Se NPs were used to trigger the immune response of cancer-bearing mice [191]. Therefore, administering biogenic Se NPs would be more efficient for orchestrating anticancer immunity compared to chemically produced counterparts. However, in our experiences Se NPs were administered orally and induced immune cell reorganization essentially through the mesenteric lymph nodes. In fact, via this strategy, the indirect effect of Se NPs on cancer is being approached. In our recent study, oral administration of Se NPs in mice demonstrated the ability to recover suppressed bone marrow cells in neutrophil cells after irradiation [206]. These results are a method of activating the body's defense against opportunistic infection threatening the survival of cancer patients undergoing radiotherapy or chemotherapy. However, many other strategies have been applied to establish and optimize the best effect of Se NPs against cancer in therapeutic and diagnostic systems.

Like other metalloid NPs, Se NPs have been used in different modalities for cancer diagnosis and therapy. Transferrin conjugated Se NPs as therapeutic agents loaded with doxorubicin showed a synergistic effect for cancer therapy with higher efficacy and fewer side effects [186]. Likewise, hyaluronic acid decorated Se NPs as a therapeutic agent demonstrated a higher tumor inhibition ratio and reduced tumor weight [187].

The mechanism that probably causes the direct anticancer effect of Se NPs is triggering apoptosis pathways. It is well documented that Se NPs induce apoptosis by depletion of mitochondrial membrane potential, reactive oxygen species (ROS) overproduction,

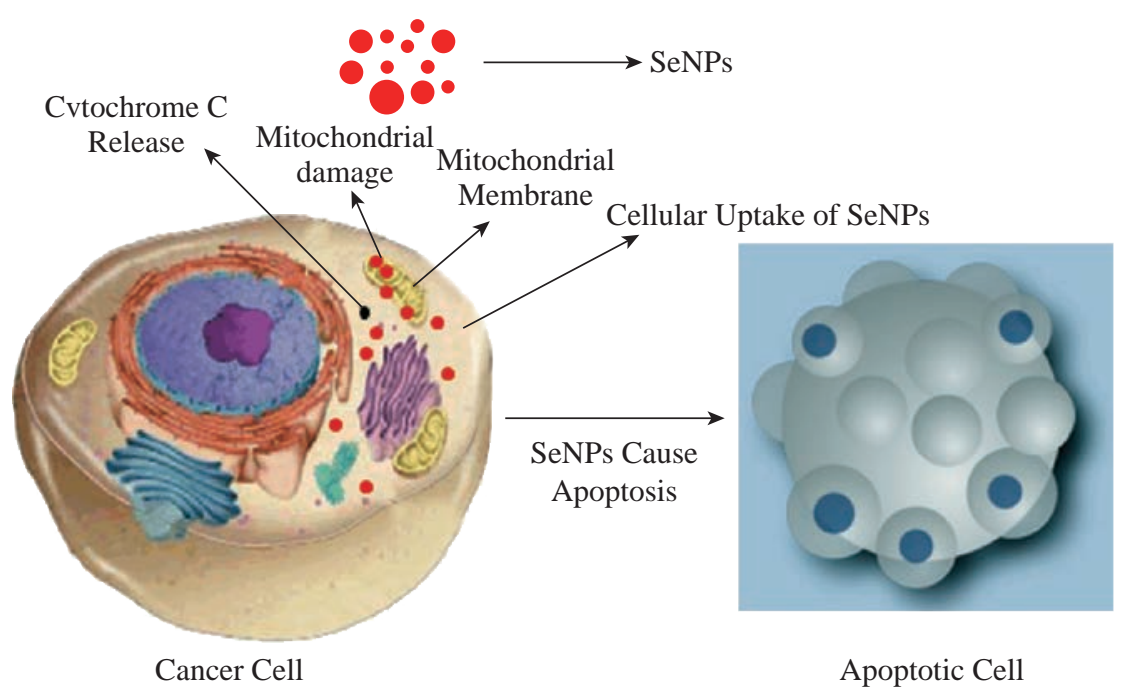

Fig. 4 Selenium NPs enter the cancer cells and accumulate in cytosol. The interaction of the SeNPs with the mitochondrial membrane results in cytochrome $\mathrm{C}$ release, initiating the intrinsic pathway of apoptosis. 
Table 3 Selenium nanoparticles and cancer research

\begin{tabular}{|c|c|c|c|c|}
\hline Type of Se NPs & Type of Cancer & Application & Consequence & Reference \\
\hline $\begin{array}{l}\text { Transferin conjugated } \\
\text { Se NPs (Tf-SeNPs) }\end{array}$ & Nude mice xenograft experiment & $\begin{array}{l}\text { As a therapeutic agents which } \\
\text { is loaded by doxorubicin }\end{array}$ & $\begin{array}{l}\text { Tf-SeNPs caused a synergistic } \\
\text { treating of cancer with higher } \\
\text { efficacy and lower side effects }\end{array}$ & 49 \\
\hline $\begin{array}{l}\text { Hyaluronic acid decorated } \\
\text { SeNPs (HA-Se) }\end{array}$ & Mice Heps tumor & $\begin{array}{l}\text { As a therapeutic in } \\
\text { comparison to } 5 \text {-fluorouracil }\end{array}$ & $\begin{array}{l}\text { HA-Se significantly reduce } \\
\text { tumor weights with higher tumor } \\
\text { inhibition ratios }\end{array}$ & 50 \\
\hline \multirow[t]{2}{*}{ Biologically prepared SeNPs } & Human breast-cancer cells (MCF-7) & $\begin{array}{l}\text { As a therapeutic agent in } \\
\text { combination with doxorubicin }\end{array}$ & $\begin{array}{l}\text { Combination of SeNPs and } \\
\text { doxorubicin shows better anticancer } \\
\text { effect than individual treatments }\end{array}$ & 51 \\
\hline & Mouse breast cancer cells (4T1) & $\begin{array}{l}\text { As a preventive agent and } \\
\text { induce better immune } \\
\text { response }\end{array}$ & $\begin{array}{l}\text { Most powerful immune responses } \\
\text { were triggered by administration of } \\
\text { Se NPs in cancer bearing mice }\end{array}$ & $52,53,54$ \\
\hline $\begin{array}{l}\text { Luminescent ruthenium(II) } \\
\text { polypyridyl functionalized } \\
\text { selenium nanoparticles } \\
\text { (Ru-SeNPs) }\end{array}$ & HepG2 and HUVEC cells & $\begin{array}{l}\text { As a blocking angiogenesis } \\
\text { agent }\end{array}$ & $\begin{array}{l}\text { Ru-SeNPs inhibits angiogenesis } \\
\text { and may be a viable drug candidate } \\
\text { in anti-angiogenesis and anticancer } \\
\text { therapies }\end{array}$ & 55 \\
\hline PEG-SeNPs & HepG2 cells & $\begin{array}{l}\text { As a therapeutic agent for } \\
\text { drug resistance cancer cells }\end{array}$ & $\begin{array}{l}\text { Using PEG200 as a surface } \\
\text { decorator of SeNPs could be a } \\
\text { highly efficient way to enhance } \\
\text { its anticancer efficacy }\end{array}$ & 56 \\
\hline Chitozan-SeNPs & A375 melanoma cells & As a therapeutic agent & $\begin{array}{l}\text { Positively charged chitosan as a } \\
\text { surface decorator could be a simple } \\
\text { and attractive approach to achieve } \\
\text { selective uptake and anticancer } \\
\text { action of nanomaterials in cancer } \\
\text { cells }\end{array}$ & 57 \\
\hline 5FU-SeNPs & A375 human melanoma cells & $\begin{array}{l}\text { As a carrier for anti cancer } \\
\text { drug }\end{array}$ & $\begin{array}{l}\text { Use SeNPs as a carrier of } 5 F U \\
\text { could be a highly efficient way to } \\
\text { achieve anticancer synergism }\end{array}$ & 58 \\
\hline CdSe/ZnS QDs & Human lung cancer & $\begin{array}{l}\text { As QDs for photodynamic } \\
\text { therapy }\end{array}$ & $\begin{array}{l}\text { UVB irradiation is the most } \\
\text { effective method for increasing the } \\
\text { potency of CdSe/ZnS QDs during } \\
\text { photodynamic cancer therapy }\end{array}$ & 59 \\
\hline $\begin{array}{l}\text { Spriulina polysaccharide } \\
\text { (SPS SeNPs) }\end{array}$ & A375 human melanoma & As a therapeutic agent & $\begin{array}{l}\text { SPS as a surface decorator could } \\
\text { be an effective way to enhance } \\
\text { the cellular uptake and anticancer } \\
\text { efficacy of nanomaterials }\end{array}$ & 60 \\
\hline $\begin{array}{l}\text { Mn-doped ZnSe d-dots } \\
\text { (Mn/ZnSe) }\end{array}$ & Human prostate cancer & As a diagnostic probe & $\begin{array}{l}\text { Mn/ZnSe d-dots were remarkably } \\
\text { efficacious for high-specificity cell } \\
\text { imaging }\end{array}$ & 61 \\
\hline CdSe quantum dots (QDs) & Breast cancer cells & $\begin{array}{l}\text { As a cancer diagnosis and } \\
\text { treatment agent }\end{array}$ & $\begin{array}{l}\text { CdSe QDs reveal considerable } \\
\text { potentials in both tumor imaging } \\
\text { and therapeutic application }\end{array}$ & 62 \\
\hline \multirow[t]{3}{*}{ SeNPs } & $\begin{array}{l}\text { MCF-7 and MDA-MB-231 breast } \\
\text { cancer cells }\end{array}$ & As a therapeutic agent & $\begin{array}{l}\text { Anticancer activity of SeNPs } \\
\text { correlates with the level of ER } \alpha \text { in } \\
\text { breast cancer cells both in vivo and } \\
\text { in vitro }\end{array}$ & 63 \\
\hline & Prostate LNCaP cancer cells & As a anti cancer agent & $\begin{array}{l}\text { SeNPs disrupt the androgen } \\
\text { receptor, and had a potential } \\
\text { application in prostate cancer } \\
\text { treatment }\end{array}$ & 64 \\
\hline & $\begin{array}{l}\text { HeLa (human cervical carcinoma) } \\
\text { cells and MDA-MB-231 (human } \\
\text { breast carcinoma) cells }\end{array}$ & $\begin{array}{l}\text { As an anti mitotic agent for } \\
\text { cancer therapy }\end{array}$ & $\begin{array}{l}\text { Using SeNPs can induce S phase } \\
\text { arrest and may be more helpful } \\
\text { in cancer chemoprevention as a } \\
\text { potential anticancer drug }\end{array}$ & 65 \\
\hline
\end{tabular}


and cytochrome C release (Fig. 4) [186]. Accumulation of intracellular ROS results in activation of the p53 and MAPKs pathways to promote cell apoptosis. However, ROS affect mitochondrial membrane potential and start a series of mitochondria-associated events and caspase activity and can be counted as another mediator of selenium treatment in cancer cells [207, 208]. Selenium, in addition to overproduction and accumulation of ROS, causes oxidative stress or endoplasmic reticulum stress and mediated cell survival by modulating $\mathrm{Ca}^{2+}$ release leading to caspase activity and apoptosis [209]. The cytotoxic effect of Se NPs demonstrated in our experiences for human and mouse cancer cells (4T1, HT29) with in vitro MTT assay may also be related to these phenomena (Fig. 5). Therefore, direct administration or intravenous (IV) injection of Se NPs to avoid tumor progress in the body can be approached and seems more efficient, although, like any other injectable drug, many parameters should be controlled before administration. Sterility, osmolarity, $\mathrm{pH}$, and volume of administration are among these parameters. For NPs, in addition to these factors, stability and aggregation must be considered.

With reference to cytotoxicity assay results in Fig. 5 for HT29 cells (human colorectal cancer) the dose of $100 \mu \mathrm{g} / \mathrm{ml}$ concentration of Se NPs almost represent $100 \%$ inhibition rate in addition to the safety of this Se NPs level that we have already observed [210]. Since colorectal cancer occurs in the gastrointestinal tract, oral administration of these NPs can also orient the drug to the target site without many IV concerns.

\section{Antimetastatic and antiangiogenic effects of Se nanoparticles}

Antimetastatic and antiangiogenic effects of Se NPs are other properties of these NPs, which are likely related to direct and indirect effects of Se NPs. In fact, Se NPs can affect the tumor not only during the early phase of development but also in late stages when the tumor becomes invasive.

We recently observed the antiangiogenic and antimetastatic effect of Se nanoparticle-enriched Lactobacillus in mice with breast tumors [191]. In our experience, the tumor metastasis in the mice treated with Se NPs enriched Lactobacillus was significantly lower than that of the mice treated with phosphate buffer solution (PBS) and the mice treated with nonSe nanoparticle-enriched Lactobacillus (Fig. 6). In addition, the rate of tumor angiogenesis in the Se nanoparticle-enriched Lactobacillus-treated mice had decreased. This result was also repeated when ruthenium (II) polypyridyl functionalized selenium NPs (Ru-Se NPs) were used against human umbilical vascular endothelial cells (HUVECs) and human hepatoma cancer cells (HepG2) [192]. Sun et al. [192] showed that Ru-Se NPs inhibit angiogenesis and are a viable drug candidate in antiangiogenesis and anticancer therapies.

In another research, we evaluated that selenium NPs can stop the attachment of cancer cells to the surface of culture flasks in in vitro assays (Fig. 7). This result, like tellurium, depends on the interaction of the surface molecules of cancer cells such as $\alpha / \beta$ integrins with Se NPs (Fig. 8). We also demonstrated that $25 \mu \mathrm{g} / \mathrm{ml}$ of Se NPs can inhibit the migration of 4T1 (mouse breast cancer) cells in scratch tests [211] after 24 hrs of culture (Fig. 9). Thus, the lower metastasis rate in the tumors of mice treated with Se NPs might be due to these phenomena [169].

However, interaction of selenium with intracellular proteins such as glutathione peroxidase (Gpx), superoxide dismutase (SOD) or catalase, and any other
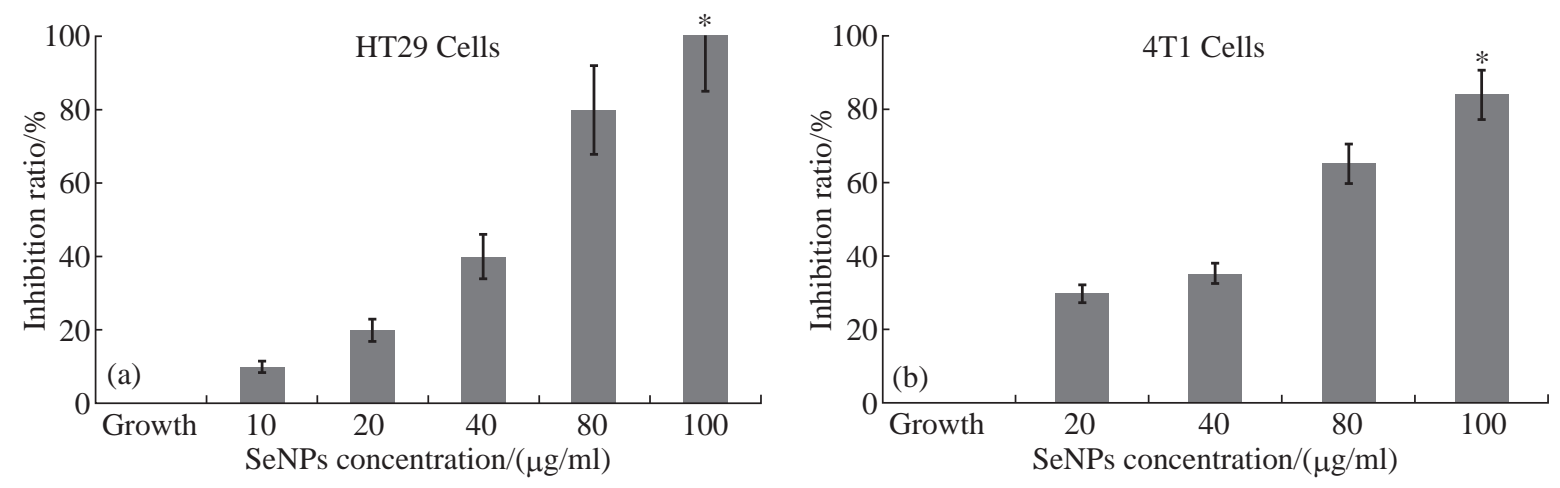

Fig. 5 Cytotoxicity assay of SeNPs on HT29 and 4T1 cell lines. In the 80 and $100 \mu \mathrm{g} / \mathrm{ml}$ concentrations of SeNPs, the maximum inhibition rate is observed. These results were obtained from triplicate culture and are shown with standard error * $(\mathrm{P} \leq 0.05)$. 

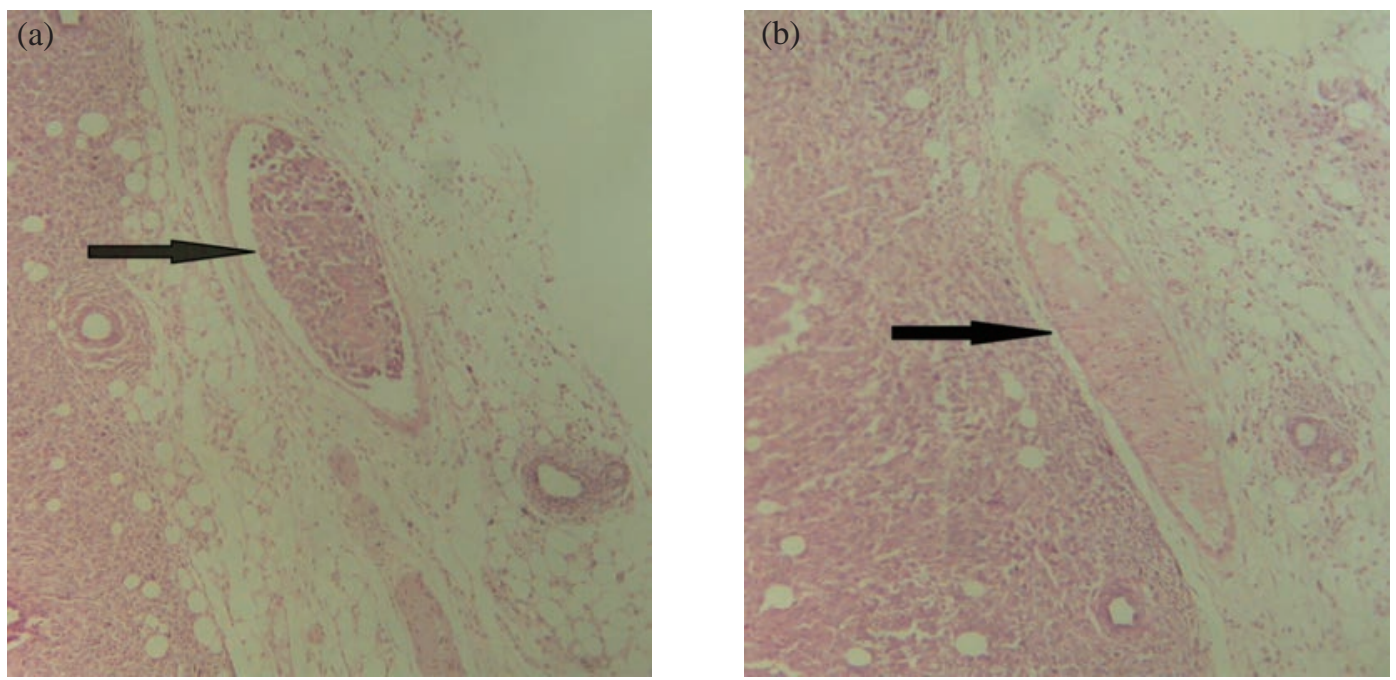

Fig. 6 Histopathological analysis of breast tumor in mice treated with SeNPs. On the left side, (a) the normal vein in the tumor tissue is shown in which no evidence of tumor invasion (as the arrow shows) is observed. On the right side, (b) the invasion of tumor cells in the vein (as the arrow shows) results in tumor metastasis in the other side of the body. Both slides were prepared from the paraffin embedded and hematoxylin and eosin (H\&E) stained breast tumor tissue of mice (induced with 4T1 cell injection). (a): tumor of control mice treated with PBS; (b): tumor of mice treated with SeNPs. The slides are shown with $40 \times$ magnification.
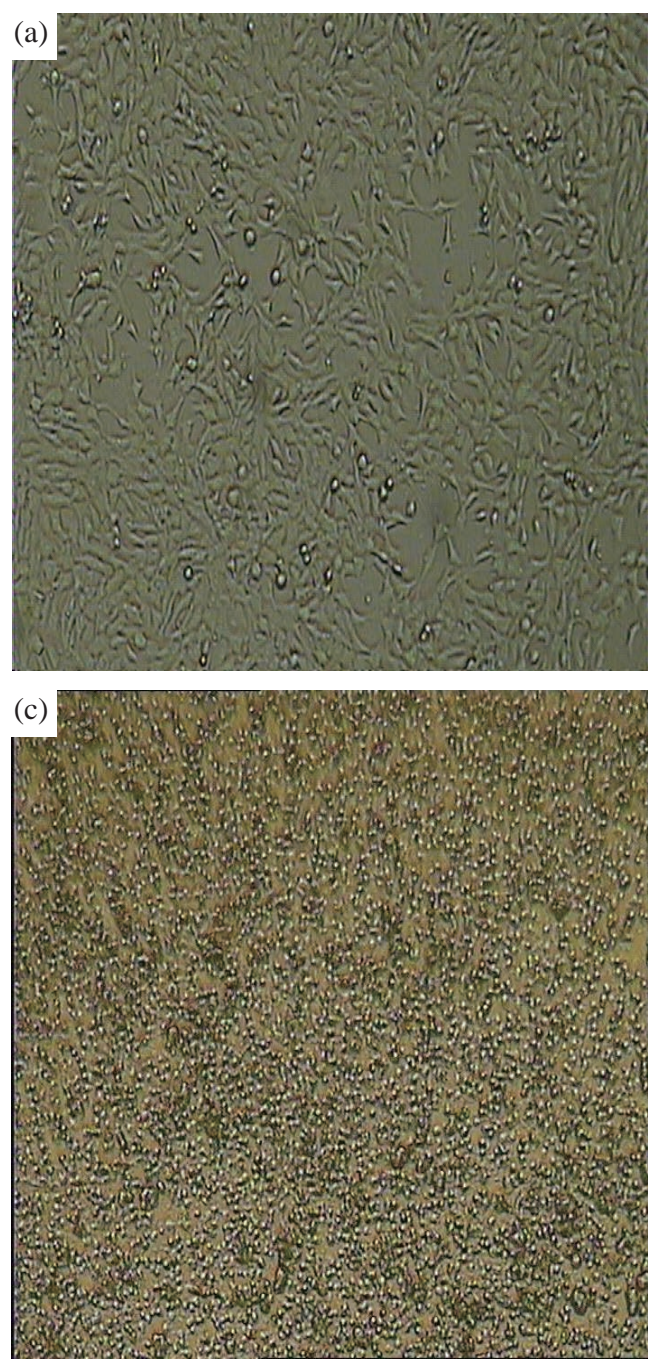
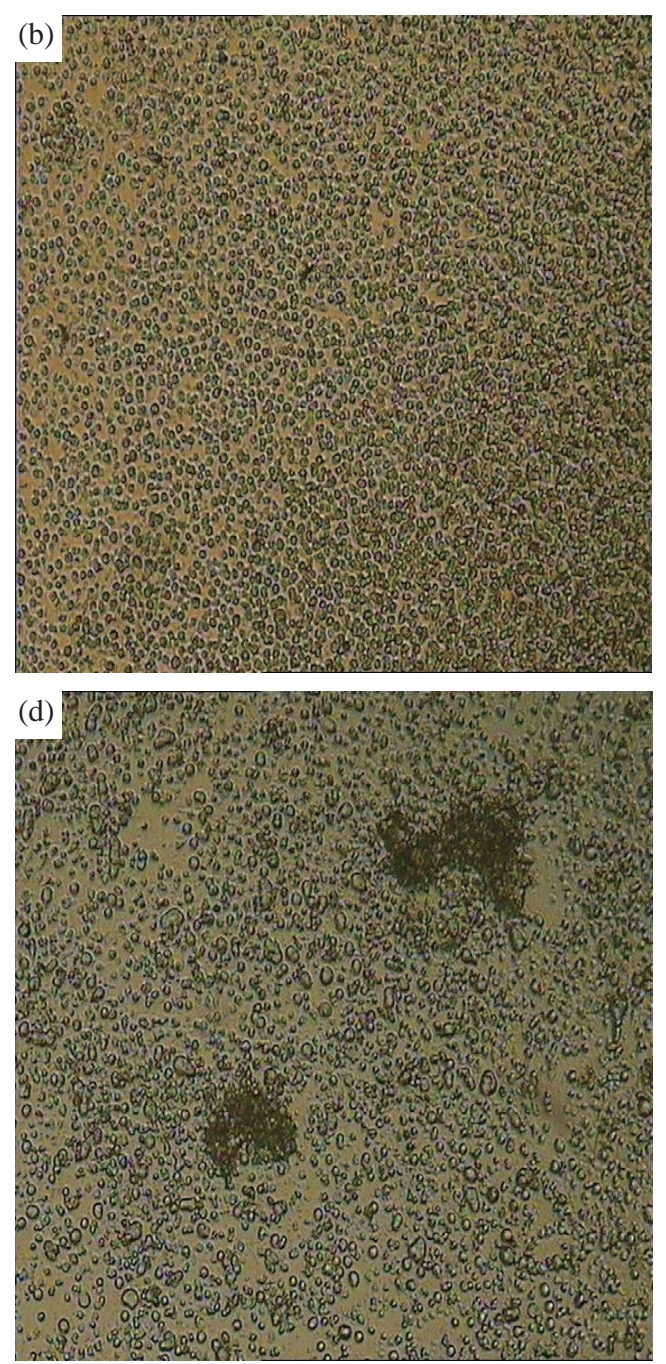

Fig. 7 Effect of different concentrations of SeNPs on the 4T1 cell line. The attachment of the cells to the surface of the flask was hindered in the treated cells: (a) untreated cells; (b) cells treated with $100 \mu \mathrm{g}$ of SeNPs; (c) cells treated with $200 \mu \mathrm{g}$ of SeNPs; and (d) cells treated with $400 \mu \mathrm{g}$ of SeNPs (most of the cells were disrupted in $400 \mu \mathrm{g}$ ). 


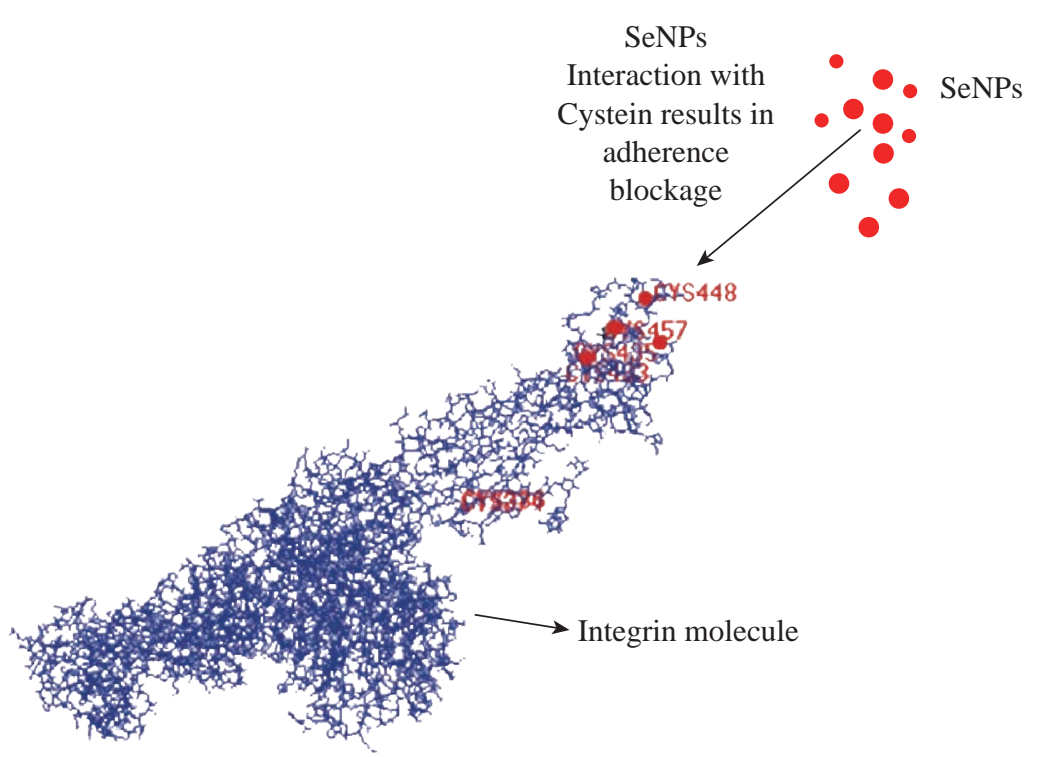

Fig. 8 Interaction of SeNPs with integrin molecules. Integrin molecules are surface molecules of cells that adhere the cells to the extracellular matrix (ECM). SeNPs interact with the cysteine residue of integrins on the surface of cancer cells and hinder the attachment of these cells, although the cysteine residues shown are not all cysteines that interacted.
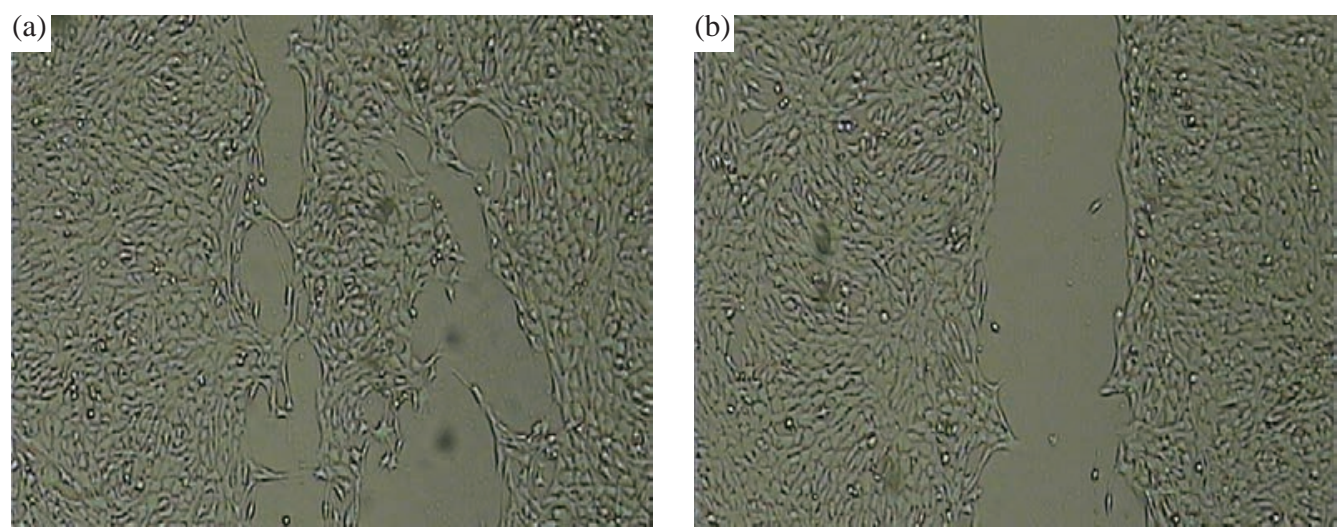

Fig. 9 The antimetastatic effect of SeNPs in the scratch test. Scratch or wound healing assays measure 2D cell migration into a wound (cell free area) created by a central linear scratch through the surface of a tissue culture well containing a $90 \%$ confluent monolayer of cells. (a) Control 4T1 cell culture after 24 hrs of scratch; (b) $25 \mu \mathrm{g} / \mathrm{ml}$ SeNPs treated $4 \mathrm{~T} 1$ cell culture after 24 hrs of scratch.

enzymes that have cysteine in their active site and inhibition of their activity results in the accumulation of ROS in the cell cytoplasm [212]. Therefore, considering the higher level of these enzymes in cancer cells due to the higher level of metabolism and mitochondrial respiration, an optimum dose of selenium may cause more toxicity for cancer cells compared to normal cells.

Given all together and considering the results of toxicological studies [185], a new modality for cancer treatment by using Se NPs, which avoids cancer development with direct and indirect effects especially with lower concern about the selenium toxicity, could be achieved. Finally, as is fundamentally expected for all nanomaterials, Se NPs provide a vast surface compared to their volume, which provides an opportunity to functionalize and target these NPs to cancer cells. The biofunctionalization of Se NPs with several biomolecules is our current research mission, and we will publish related results soon.

\section{Conclusions}

Although inorganic NPs may seem useful tools for cancer imaging and diagnosis, the capacity of these agents does not stop there. Attacking cancerous cells as anticancer drugs or carriers for anticancer medications has also shown promising results. Albeit, to the best of the authors' knowledge there is a hidden trend to use nanoparticles more for diagnostic oncology and although current available chemotherapeutic medications do not distinguish between cancerous 
and normal cells and have many side effects, in the case of nanoparticles there is a more conservatism for therapeutic application. However, we believe that this concern is not a case especially when metal NPs are used. In fact, although the fate of NPs in the body and tissue distribution of these agents and attachment of NPs to natural proteins of human body (protein cornea) are considered as big concerns, metal NPs have safe properties in this regard. Taken together it is predictable that in the near future, inorganic NPs will likely open a new window not only as diagnostic agents but also as useful agents in cancer treatment.

\section{Acknowledgements}

This work was supported financially by the grant from Iran National Science Foundation (INSF), Tehran, Iran.

\section{References}

[1] T.K. Sau, A.L. Rogach, Nonspherical noble metal NPs: colloid-chemical synthesis and morphology control. Advanced Materials, 2010, 22: 1781-1804.

[2] H. Schmidt, NPs by chemical synthesis, processing to materials and innovative applications. Applied Organometallic Chemistry, 2001, 15: 331-343.

[3] A.B.D. Pandey. Synthesis of zinc-based nanomaterials: a biological perspective. IET Nanobiotechnology, 2012, 6: 144-148.

[4] M. Shakibaie, H. Forootanfar, K.M. Moghaddam, et al., Green synthesis of gold NPs by the marine microalga Tetraselmis suecica. Biotechnology and Applied Biochemistry, 2010, 57: 71-75.

[5] B. Kang, M.A. Mackey, M.A. El-Sayed, Nuclear targeting of gold NPs in cancer cells induces DNA damage, causing cytokinesis arrest and apoptosis. Journal of the American Chemical Society, 2010, 132: 1517-1519.

[6] M.M. Yallapu, S.P. Foy, T.K. Jain, et al., PEG-functionalized magnetic NPs for drug delivery and magnetic resonance imaging applications. Pharmacological Research, 2010, 27: 2283-2295.

[7] P.R. Gil, D. Huhn, L.L. Del Mercato, et al., Nanopharmacy: Inorganic nanoscale devices as vectors and active compounds. Pharmacological Research, 2010, 62: $115-125$.

[8] S. Bhattacharyya, R.A. Kudgus, R. Bhattacharya, et al., Inorganic NPs in cancer therapy. Pharmacological Research, 2011, 28: 237-259.

[9] N.L. Rosi, C.A. Mirkin, Nanostructures in biodiagnostics. Chemical Reviews, 2005, 105: 1547-1562.

[10] H.C. Huang, S. Barua, G. Sharma, et al., Inorganic NPs for cancer imaging and therapy. Journal of Control Release, 2011, 155: 344-357.

[11] K.H. Bae, H.J. Chung, and T.G. Park, Nanomaterials for Cancer Therapy and Imaging. Molecules and Cells, 2011, 31: 295-302.

[12] M. Valden, X. Lal, D.W. Goodman, Onset of catalytic activity of gold clusters on titania with the appearance of nonmetallic properties. Science, 1998, 281: 1647-1650.

[13] M.A. El-Sayed, Some interesting properties of metals confined in time and nanometer space of different shapes.
Accounts of Chemical Research, 2001, 34: 257-264.

[14] D.L. Feldheim, C.A. Foss Jr., Metal NPs: synthesis characterization, and applications. Marcel Dekker, 2002.

[15] C.J. Murphy, Nanocubes and Nanoboxes. Science, 2002, 298: 2139-2141.

[16] S.T. Selvan, T.T. Tan, D.K. Yi, et al., Functional and multifunctional nanoparticles for bioimaging and biosensing. Langmuir, 2010, 26: 11631-11641.

[17] Y. Liu, M. Xu, Q. Chen, et al., Gold nanorods/mesoporous silica-based nanocomposite as theranostic agents for targeting near-infrared imaging and photothermal therapy induced with laser. International Journal of Nanomedicine, 2015, 10: 4747-4761.

[18] X. Huang, P.K. Jain, I.H. El-Sayed, et al., Gold NPs: interesting optical properties and recent applications in cancer diagnostics and therapy. Nanomedicine, 2007, 2: 681-693.

[19] J.F. Hainfeld, D.N. Slatkin, and H.M. Smilowitz, The use of gold NPs to enhance radiotherapy in mice. Physics in Medicine and Biology, 2004, 49: 309-315.

[20] J.F. Hainfeld, F.A. Dilmanian, D.N. Slatkin, et al., Radiotherapy enhancement with gold NPs. Journal of Pharmacy and Pharmacology, 2008, 60: 977-985.

[21] L.R. Hirsch, R.J. Stafford, J.A. Bankson, et al., Nanoshellmediated near-infrared thermal therapy of tumors under magnetic resonance guidance. Proceedings of the National Academy of Sciences U.S.A, 2003, 100: 1354913554.

[22] X. Huang, I.H. El-Sayed, W. Qian, et al., Cancer cell imaging and photothermal therapy in the near-infrared region by using gold nanorods. Journal of the American Chemical Society, 2006, 128: 2115-2120.

[23] M.S. Yavuz, Y. Cheng, J. Chen, et al., Gold nanocages covered by smart polymers for controlled release with near-infrared light. Nature Materials, 2009, 8: 935-939.

[24] G. Han, P. Ghosh, and V.M. Rotello, Multi-functional gold NPs for drug delivery. Advances in Experimental Medicine and Biology, 2007, 620: 48-56.

[25] M. Thomas, A.M. Klibanov, Conjugation to gold NPs enhances polyethylenimine's transfer of plasmid DNA into mammalian cells. Proceedings of the National Academy of Sciences U.S.A, 2003, 100: 9138-9143.

[26] Z.Yang, D. Gao , Z. Cao, et al., Drug and gene codelivery systems for cancer treatment. Biomaterial Science, 2015, 3: 1035-1049.

[27] A.S. Arbab, W. Liu, and J.A. Frank. Cellular magnetic resonance imaging: current status and future prospects. Expert Review of Medical Devices, 2006, 3: 427-439.

[28] K. Kan-Dapaah, N. Rahbar, and W. Soboyejo, Novel magnetic heating probe for multimodal cancer treatment. Medical Physics, 2015, 42: 2203-2211.

[29] T.K. Sau, A.L. Rogach, Nonspherical noble metal NPs: colloid-chemical synthesis and morphology control. Advanced Materials, 2010, 22: 1781-1804.

[30] S. Patra, S. Mukherjee, A.K. Barui, et al., Green synthesis, characterization of gold and silver NPs and their potential application for cancer therapeutics. Materials Science and Engineering C: Materials for Biological Applications, 2015, 53: 298-309.

[31] R.A. Sperling, W.J. Parak, Surface modification, functionalization and bioconjugation of colloidal inorganic NPs. Philosophical Transactions of the Royal Society A, 2010, 368: 1333-1383.

[32] E. Katz, I. Willner, Integrated nanoparticle-biomolecule hybrid systems: synthesis, properties, and applications. Angewandte Chemie International Edition, 2004, 43: 6042-6108.

[33] C.M. Niemeyer, NPs, proteins, and nucleic acids: biotechnology meets materials science. Angewandte Chemie International Edition, 2001, 40: 4128-4158. 
[34] K. Naka, H. Itoh, Y. Tampo, et al., Effect of gold NPs as a support for the oligomerization of L-cysteine in an aqueous solution. Langmuir, 2003, 19: 5546-5549.

[35] P. Ghosh, G. Han, M. De, et al., Gold NPs in delivery applications. Advanced Drug Delivery Reviews, 2008, 60: 1307-1315.

[36] N. Nishiyama, Nanomedicine: nanocarriers shape up for long life. Nature Nanotechnology, 2007, 2: 203-204.

[37] H. Chen, L. Shao, T. Ming, et al., Understanding the photothermal conversion efficiency of gold nanocrystals. Small, 2010, 6: 2272-2280.

[38] E.S. Day, J.G. Morton, and J.L. West, NPs for thermal cancer therapy. Journal of Biomechanical Engineering, 2009, 131: 740011.

[39] K.K. Jain, Applications of nanobiotechnology in clinical diagnostics. Clinical Chemistry, 2007, 53: 2002-2009.

[40] K.K. Jain, Nanomedicine: application of nanobiotechnology in medical practice. Medical Principles and Practice, 2008, 17: 89-101.

[41] P.V. Baptista, G. Doria, P. Quaresma, et al., NPs in molecular diagnostics. Progress in Molecular Biology and Translational Science. 2011, 104: 427-488.

[42] C. Jianrong, M. Yuqing, H. Nongyue, et al., Nanotechnology and biosensors. Biotechnology Advances, 2004, 22: 505-518.

[43] B.S. Sekhon, Metalloid compounds as drugs. Research in Pharmaceutical Sciences, 2013, 8: 145-158.

[44] N.C. Loyd, H.W. Morgan, B.K. Nicholson, et al., The composition of Ehrlich's salvarsan: resolution of a century-old debate. Angewandte Chemie International Edition in English, 2005, 44: 941-944.

[45] S. Soflaei, A. Dalimi, F. Ghaffarifar, et al., In vitro antiparasitic and apoptotic effects of antimony sulfide NPs on Leishmania infantum. Journal of Parasitology Research, 2012, 756568.

[46] R.L. Cunha, I.E. Gouvea, and L. Juliano, A glimpse on biological activities of tellurium compounds. Anais da Academia Brasileira de Ciências, 2009, 81: 393-407.

[47] Z.P. Xu, Q.H. Zeng, G.Q. Lu, et al., Inorganic NPs as carriers for efficient cellular delivery. Chemical Engineering Science, 2006, 61: 1027-1040.

[48] K. Byrappa, S. Ohara, and T. Adschiri, NPs synthesis using supercritical fluid technology-towards biomedical applications. Advanced Drug Delivery Reviews, 2008, 60: 299-307.

[49] O. Rabin, J.M. Perez, J. Grimm, et al., An X-ray computed tomography imaging agent based on longcirculating bismuth sulphide NPs. Nature Materials, 2006, 5: 118-122.

[50] C.J. Jia, F. Schüth, Colloidal metal NPs as a component of designed catalyst. Physical Chemistry Chemical Physics, 2011, 13: 2457-2487.

[51] M.A. Faramarzi, A. Sadighi, Insights into biogenic and chemical production of inorganic nanomaterials and nanostructures. Advances in Colloid and Interface Science, 2013, 189: 1-20

[52] L.T. Lu, L.D. Tung, I. Robinson, et al., Size and shape control for water-soluble magnetic cobalt NPs using polymer ligands. Journal of Materials Chemistry, 2008, 18: 2453-2458.

[53] M. Brust, M. Walker, D. Bethell, et al., Synthesis of thiol-derivatised gold NPs in a two-phase Liquid-Liquid system. Journal of the Chemical Society, Chemical Communications, 1994, 801-802.

[54] N.T.K. Thanh, L.A.W. Green, Functionalisation of NPs for biomedical applications. Nano Today, 2010, 5: 213230.

[55] N.R. Jana, L. Gearheart, and C.J. Murphy, Wet chemical synthesis of high aspect ratio cylindrical gold nanorods. The Journal of Physical Chemistry B, 2001, 105: 4065-
4067.

[56] S.K. Das, E. Marsili, A green chemical approach for the synthesis of gold NPs: characterization and mechanistic aspect. Reviews in Environmental Science and Biotechnology, 2010, 9: 199-204.

[57] J. Bain, S.S. Staniland, Bioinspired nanoreactors for the biomineralisation of metallic-based NPs for nanomedicine. Physical Chemistry Chemical Physics, 2015, 17: 15508-15521.

[58] V. Bansal, A. Bharde, R. Ramanathan, et al., Inorganic materials using 'unusual' microorganisms. Advances in Colloid and Interface Science, 2012, 179: 150-168.

[59] A. Prakash, S. Sharma, N. Ahmad, et al., Bacteria mediated extracellular synthesis of metallic NPs. International Research Journal of Biotechnology, 2010, 1: 71-79.

[60] M. Ashokkumar, Microbial synthesis of silver NPs by Bacillus sp. Journal of Nanoparticle Research, 2009, 11: 1811-1815.

[61] N. Krumov, S. Oder, I.P. Nochta, et al., Accumulation of CdS NPs by yeasts in a fed-batch bioprocess. Journal of Biotechnology, 2007, 132: 481-487.

[62] D.H. Nies, Microbial heavy-metal resistance. Applied Microbiology and Biotechnology, 1999, 51: 730-750.

[63] D. Jaysankar, N. Ramaiah, and L.Vardanyan, Detoxification of toxic heavy metals by marine bacteria highly resistant to mercury. Marine Biotechnology, 2008, 10: 471-477.

[64] L. Levina, V. Sukhovatkin, S. Musikhin, et al., Efficient infrared-emitting PbS quantum dots grown on DNA and stable in aqueous solution and blood plasma. Advanced Materials, 2005, 15: 1854-1857.

[65] A. Kumar, B. Singh, Synthesis and photophysics of red emitting RNA templated PbSe nanostructures. Chemical Communications, 2011, 47: 4144-4146.

[66] S.K. Srivastava, R. Yamada, C. Ogino, et al., Biogenic synthesis and characterization of gold NPs by Escherichia coli K12 and its heterogeneous catalysis in degradation of 4-nitrophenol. Nanoscale Research Letters, 2013, 8: 70.

[67] K. Sokolov, M. Follen, J. Aaron, et al., Real-time vital optical imaging of precancer using anti-epidermal growth factor receptor antibodies conjugated to gold NPs. Cancer Research, 2003, 63: 1999-2004.

[68] I.H. El-Sayed, X. Huang, and M.A. El-Sayed, Surface plasmon resonance scattering and absorption of antiEGFR antibody conjugated gold NPs in cancer diagnostics: applications in oral cancer. Nano Letter, 2005, 5: 829-834.

[69] I.H. El-Sayed, X. Huang, and M.A. El-Sayed, Selective laser photo-thermal therapy of epithelial carcinoma using anti-EGFR antibody conjugated gold NPs. Cancer Letter, 2006, 28: 129-135.

[70] Y. Wang, Y. Liu, H. Luehmann, et al., Evaluating the pharmacokinetics and in vivo cancer targeting capability of $\mathrm{Au}$ nanocages by positron emission tomography imaging. ACS Nano, 2012, 24: 5880-5888.

[71] M. Everts, V. Saini, J.L. Leddon, et al., Covalently linked $\mathrm{Au}$ NPs to a viral vector: potential for combined photothermal and gene cancer therapy. Nano Letter, 2006, 6: 587-591.

[72] M.Y. Lan, Y.B. Hsu, C.H. Hsu, et al., Induction of apoptosis by high-dose gold NPs in nasopharyngeal carcinoma cells. Auris Nasus Larynx, 2013, 40: 563-568.

[73] M. Benito, V. Martín, M.D. Blanco, et al., Cooperative effect of 5-aminolevulinic acid and gold NPs for photodynamic therapy of cancer. Journal of Pharmaceutical Sciences, 2013, 102: 2760-2769.

[74] P. Karuppaiya, E. Satheeshkumar, W.T. Chao, et al., Antimetastatic activity of biologically synthesized gold NPs on human fibrosarcoma cell line HT-1080. Colloids and 
Surfaces B: Biointerfaces, 2013, 110: 163-170.

[75] E. Amato, A. Italiano, S. Leotta, et al., Monte Carlo study of the dose enhancement effect of gold NPs during X-ray therapies and evaluation of the anti-angiogenic effect on tumour capillary vessels. Journal of X-Ray Science and Technology, 2013, 21: 237-247.

[76] J. Liu, W. Zhang, H. Zhang, et al., A multifunctional nanoprobe based on $\mathrm{Au}-\mathrm{Fe}_{3} \mathrm{O}_{4} \mathrm{NPs}$ for multimodal and ultrasensitive detection of cancer cells. Chemical Communications (Camb), 2013, 49: 4938-4940.

[77] R. Govender, A. Phulukdaree, R.M. Gengan, et al., Silver NPs of Albizia adianthifolia: the induction of apoptosis in human lung carcinoma cell line. Journal of Nanobiotechnology, 2013, 11: 5.

[78] I. Sur, M. Altunbek, M. Kahraman, et al., The influence of the surface chemistry of silver NPs on cell death. Nanotechnology, 2012, 21: 375102.

[79] R. Lu, D. Yang, D. Cui, et al., Egg white-mediated green synthesis of silver NPs with excellent biocompatibility and enhanced radiation effects on cancer cells. International Journal of Nanomedicine, 2012, 7: 21012107.

[80] L.A. Austin, B. Kang, C.W. Yen, et al., Plasmonic imaging of human oral cancer cell communities during programmed cell death by nuclear-targeting silver NPs. Journal of the American Chemical Society, 2011, 9: 17594-17597.

[81] S.C. Boca, M. Potara, A.M. Gabudean, et al., Chitosancoated triangular silver NPs as a novel class of biocompatible, highly effective photothermal transducers for in vitro cancer cell therapy. Cancer Letter, 2011, 311: 131-140.

[82] L. Liu, F. Ni, J. Zhang, et al., Silver nanocrystals sensitize magnetic-nanoparticle-mediated thermo-induced killing of cancer cells. Acta Biochimica et Biophysica Sinica, 2011, 43: 316-323.

[83] P. Sanpui, A. Chattopadhyay, S.S. Ghosh, Induction of apoptosis in cancer cells at low silver nanoparticle concentrations using chitosan nanocarrier. ACS Applied Materials \& Interfaces, 2011, 2: 218-228.

[84] H. Wang, Y. Zhang, H. Yu, et al., Label-free electrochemical immunosensor for prostate-specific antigen based on silver hybridized mesoporous silica NPs. Analytical Biochemistry, 2013, 434: 123-127.

[85] E. Locatelli, F. Broggi, J. Ponti, et al., Lipophilic silver NPs and their polymeric entrapment into targetedPEG-based micelles for the treatment of glioblastoma. Advanced Healthcare Materials, 2012, 1: 342-347.

[86] S.N. Ostad, S. Dehnad, Z.E. Nazari, et al., Cytotoxic activities of silver NPs and silver ions in parent and tamoxifen-resistant T47D human breast cancer cells and their combination effects with tamoxifen against resistant cells. Avicenna Journal of Medical Biotechnology, 2010, 4: 187-196.

[87] V. Economopoulos, Y. Chen, C. McFadden, et al., MRI detection of nonproliferative tumor cells in lymph node metastases using iron oxide particles in a mouse model of breast cancer. Translational Oncology, 2013, 6: 347-354.

[88] C.D. Burford, K.D. Bhattacharyya, N. Boriraksantikul, et al,. Nanoparticle mediated thermal ablation of breast cancer cells using a nanosecond pulsed electric field. IEEE Transactions on NanoBioscience, 2013, 2: 112-118.

[89] S.A. Meenach, J.M. Shapiro, J.Z. Hilt, et al., Characterization of PEG-iron oxide hydrogel nanocomposites for dual hyperthermia and paclitaxel delivery. Journal of Biomaterials Science, Polymer Edition, 2013, 24: 11121126.

[90] X. Wang, B. Chen, X. Yang,et al., Functionalized superparamagnetic NPs for highly-efficient gene delivery. Journal of Nanoscience and Nanotechnology, 2013, 2:
746-750.

[91] L. Zhao, M. Huo, J. Liu, et al., In vitro investigation on the magnetic thermochemotherapy mediated by magnetic NPs combined with methotrexate for breast cancer treatment. Journal of Nanoscience and Nanotechnology, 2013, 2: 741-745.

[92] K. Hayashi, M. Nakamura, W. Sakamoto, et al., Superparamagnetic nanoparticle clusters for cancer theranostics combining magnetic resonance imaging and hyperthermia treatment. Theranostics, 2013, 3: 366-376.

[93] S. Mahdihassan, Cinnabar-gold as the best alchemical drug of longevity, called Makaradhwaja in India. American Journal of Chinese Medicine, 1985, 13: 93-108.

[94] S.P. Fricker, R.G. Buckley, Comparison of two colorimetric assays as cytotoxicity endpoints for an in vitro screen for antitumour agents. Anticancer Research, 1996, 16: 3755-3760.

[95] D.T. Felson, J.J. Anderson, and R.F. Meenan, The comparative efficacy and toxicity of second-line drugs in rheumatoid arthritis. Results of two metaanalyses. Arthritis \& Rheumatology, 1990, 33: 1449-1461.

[96] R. Bhattacharya, P. Mukherjee, Biological properties of “naked” metal NPs. Advanced Drug Delivery Reviews, 2008, 60: 1289-1306.

[97] D. Cabuzu, A. Cirja, R. Puiu et al., Biomedical applications of gold NPs. Current Topics in Medicinal Chemistry, 2015, 16: 1605-1613.

[98] Y. Levy, J.N. Onuchic, Mechanisms of protein assembly: lessons from minimalist models. Accounts of Chemical Research, 2006, 39: 135-142.

[99] A. Hamilton, G. Hortobagyi, Chemotherapy: what progress in the last 5 years? Journal of Clinical Oncology, 2005, 23: 1760-1775.

[100] I.H. El-Sayed, X. Huang, and M.A. El-Sayed, Selective laser photo-thermal therapy of epithelial carcinoma using anti-EGFR antibody conjugated gold NPs. Cancer Letter, 2006, 239: 129-135.

[101] C.R. Patra, R. Bhattacharya, D. Mukhopadhyay, et al., Fabrication of gold NPs for targeted therapy in pancreatic cancer. Advanced Drug Delivery Reviews, 2010, 62: 346361.

[102] C.J. Gannon, C.R. Patra, R. Bhattacharya, et al., Intracellular gold NPs enhance non-invasive radiofrequency thermal destruction of human gastrointestinal cancer cells. Journal of Nanobiotechnology, 2008, 6: 2.

[103] N. Chattopadhyay, Z. Cai, Y.L. Kwon, et al., Molecularly targeted gold NPs enhance the radiation response of breast cancer cells and tumor xenografts to X-radiation. Breast Cancer Research and Treatment, 2013, 137: 81-91.

[104] P.K. Jain, I.H. El-Sayed, and M.A. El-Sayed, Au NPs target cancer. Nano Today, 2007, 2: 18-29.

[105] D.P. O’Neal, L.R. Hirsch, N.J. Halas, et al., Photo-thermal tumor ablation in mice using near infrared-absorbing NPs. Cancer Letter, 2004, 209: 171-176.

[106] I.H. El-Sayed, X. Huang, and M.A. El-Sayed, Surface plasmon resonance scattering and absorption of antiEGFR antibody conjugated gold NPs in cancer diagnostics: applications in oral cancer. Nano Letter, 2005, 5: 829-834.

[107] Y. Wang, X. Xie, X. Wang, et al., Photoacoustic tomography of a nanoshell contrast agent in the in vivo rat brain. Nano Letter, 2004, 4: 1689-1692.

[108] W. Faulk, G. Taylor, An immunocolloid method for the electron microscope. Immunochemistry, 1971, 8: 10811083.

[109] C. You, C. Han, X. Wang, et al., The progress of silver NPs in the antibacterial mechanism, clinical application and cytotoxicity. Molecular Biology Reports, 2012, 39: 9193-9201.

[110] M. Ahamed , M.S. Alsalhi, and M.K. Siddiqui, Silver 
nanoparticle applications and human health. Clinica Chimica Acta, 2010, 14: 1841-1848.

[111] H.J. Johnston, G. Hutchison, F.M. Christensen, et al., A review of the in vivo and in vitro toxicity of silver and gold particulates: particle attributes and biological mechanisms responsible for the observed toxicity. Critical Reviews in Toxicology, 2010, 40: 328-346.

[112] S.C.G. K. Daniel, R. Kumar, V. Sathish, et al., Green synthesis (Ocimum tenuiflorum) of silver NPs and toxicity studies in zebra fish (Danio rerio) model. International Journal of Nanoscience and Nanotechnology, 2011, 2: 103-117.

[113] P. Bourrinet, H.H. Bengele, B. Bonnemain, et al., Preclinical safety and pharmacokinetic profile of ferumoxtran-10, an ultrasmall superparamagnetic iron oxide magnetic resonance contrast agent. Investigative Radiology, 2006, 41: 313-324.

[114] R. Vaidyanathan, K. Kalishwaralal, S. Gopalram, et al., Nanosilver-the burgeoning therapeutic molecule and its green synthesis. Biotechnology Advances, 2009, 27: 924937.

[115] M. Jeyaraj, G. Sathishkumar, G. Sivanandhan, et al., A. Biogenic silver NPs for cancer treatment: an experimental report. Colloids and Surfaces B: Biointerfaces, 2013, 106: 86-92.

[116] O.V. Melnikov, O.Y. Gorbenko, M.N. Markelova, et al,. Ag-doped manganite NPs: new materials for temperaturecontrolled medical hyperthermia. Journal of Biomedical Materials Research A, 2009, 91: 1048-1055.

[117] P.V.A. Rani, G.L.K. Mun, M.P. Hande, et al., Cytotoxicity and genotoxicity of silver NPs in human cells. ACS Nano, 2009, 3: 279-290.

[118] T. Xia, M. Kovochich, J. Brant, et al., Comparison of the abilities of ambient and manufactured NPs to induce cellular toxicity according to an oxidative stress paradigm. Nano Letter, 2006, 6: 1794-1807.

[119] M.F. Caroline, J.S. Graeme, G.F.G.T. George, et al., Effects of anti-epilepticdrugs on glutamine synthetase activity in mouse brain. British Journal of Pharmacology, 1999, 126: 1634-1638.

[120] R. Ranganathan, S. Madanmohan, A. Kesavan, et al., Nanomedicine: towards development of patient-friendly drug-delivery systems for oncological applications. International Journal of Nanomedicine, 2012, 7: 10431060 .

[121] Q. Wu, H. Cao, Q. Luan, et al., Biomolecule-assisted synthesis of water soluble silver NPs and their biomedical applications. Inorganic Chemistry, 2008, 47: 5882-5888.

[122] A.N. Ananth, S.C.G. K. Daniel, T.A. Sironmani, et al., PVA and BSA stabilized silver NPs based surfaceenhanced plasmon resonance probes for protein detection. Colloid Surface B, 2011, 85: 138-144.

[123] G.F. Goya, T.S. Berquo, F.C. Fonseca, Static and dynamic magnetic properties of spherical magnetite NPs. Journal of Applied Physics, 2003, 94: 3520-3527.

[124] F. Yang, C. Jin, S. Subedi, et al., Emerging inorganic nanomaterials for pancreatic cancer diagnosis and treatment. Cancer Treatment Reviews, 2012, 38: 566-579.

[125] A.K .Gupta, M. Gupta, Synthesis and surface engineering of iron oxide NPs for biomedical applications. Biomaterials, 2005, 26: 3995-4021.

[126] D.R. Wahajuddin, S. Arora, Superparamagnetic iron oxide NPs: magnetic nanoplatforms as drug carriers. International Journal of Nanomedicine, 2012, 7: 34453471.

[127] K. Pusic, Z. Aguilar, J. McLoughlin, et al., Iron oxide NPs as a clinically acceptable delivery platform for a recombinant blood-stage human malaria vaccine. FASEB Journal, 2013, 27: 1153-1166.

[128] A. Mandal, S. Sekar, M. Kanagavel, et al., Collagen based magnetic nanobiocomposite as MRI contrast agent and for targeted delivery in cancer therapy. Biochimica et Biophysica Acta, 2013, 1830: 4628-4633.

[129] D. Bhattacharya, M. Das, D. Mishra, et al., Folate receptor targeted, carboxymethyl chitosan functionalized iron oxide NPs: a novel ultradispersed nanoconjugates for bimodal imaging. Nanoscale, 2011, 3: 1653-1662.

[130] M. Chamundeeswari, T.P. Sastry, B.S. Lakhsmi, et al., Iron NPs from animal blood for cellular imaging and targeted delivery for cancer treatment. Biochimica et Biophysica Acta, 2013, 1830: 3005-3010.

[131] A.M. El-Toni, M.A. Ibrahim, J.P. Labis, et al., Optimization of synthesis parameters for mesoporous shell formation on magnetic nanocores and their application as nanocarriers for docetaxel cancer drug. International Journal of Molecular Sciences, 2013, 30: 11496-11509.

[132] H. Zhao, Z. Li, B. Yang et al., Synthesis of dualfunctional targeting probes for cancer theranostics based on iron oxide NPs coated by centipede-like polymer connected with $\mathrm{pH}$-responsive anticancer drug. Journal of Biomaterials Science, Polymer Edition, 2015, 7: 1-30.

[133] A.H. Lu, E.L. Salabas, and F. Schuth, Magnetic NPs: synthesis, protection, functionalization, and application. Angewandte Chemie International Edition in English, 2007, 46: 1222-1244.

[134] O.S. Nielsen, M. Horsman, and J. Overgaard, A future for hyperthermia in cancer treatment? European Journal of Cancer, 2001, 37: 1587-1589.

[135] A. Ito, M. Shinkai, H. Honda, et al., Heat-inducible TNFalpha gene therapy combined with hyperthermia using magnetic NPs as a novel tumor-targeted therapy. Cancer Gene Therapy, 2001, 8: 649-654.

[136] H.L.R. Luccioni, M.L. Esteves, J.M. Vega, et al., Enhanced reduction in cell viability by hyperthermia induced by magnetic NPs. International Journal of Nanomedicine, 2011, 6: 373-380.

[137] C.A. Quinto, P. Mohindra, S. Tong et al., Multifunctional superparamagnetic iron oxide NPs for combined chemotherapy and hyperthermia cancer treatment. Nanoscale, 2015, 7: 12728-12736.

[138] A. Liberman, H.P. Martinez, C.N. Ta, et al., Hollow silica and silica-boron nano/microparticles for contrastenhanced ultrasound to detect small tumors. Biomaterials, 2012, 33: 5124-5129.

[139] A.V. Efremenko, A.A. Ignatova, A.A. Borsheva, et al., Cobalt bis(dicarbollide) versus closo-dodecaborate in boronated chlorin e(6) conjugates: implications for photodynamic and boron-neutron capture therapy. Photochemical \& Photobiological Sciences, 2012, 11: 645-652.

[140] C.H. Lai, Y.C. Lin, F.I. Chou, et al ., Design of multivalent galactosyl carborane as a targeting specific agent for potential application to boron neutron capture therapy. Chemical Communications (Camb), 2012, 48: 612-614.

[141] C. Hong, C. Lee, In vitro cell tests of pancreatic malignant tumor cells by photothermotherapy based on DMSO porous silicon colloids. Lasers in Medical Science, 2013, 20: 221-223.

[142] E. Secret, M. Maynadier, A. Gallud, et al., Anionic porphyrin-grafted porous silicon NPs for photodynamic therapy. Chemical Communications (Camb), 2013, 49: 4202-4204.

[143] C. Qian, Y. Wang, Y. Chen, et al., Suppression of pancreatic tumor growth by targeted arsenic delivery with anti-CD44v6 single chain antibody conjugated NPs. Biomaterials, 2013, 34: 6175-6184.

[144] R.W. Ahn, F. Chen, H. Chen, et al., A novel nanoparticulate formulation of arsenic trioxide with enhanced therapeutic efficacy in a murine model of breast 
cancer. Clinical Cancer Research, 2010, 16: 3607-3617.

[145] H. Chen, R. Ahn, J. Van den Bossche, et al., Folatemediated intracellular drug delivery increases the anticancer efficacy of nanoparticulate formulation of arsenic trioxide. Molecular Cancer Therapeutics, 2009, 8: 1955-1963.

[146] Z.Y. Wang, J. Song, D.S. Zhang, Nanosized $\mathrm{As}_{2} \mathrm{O}_{3} / \mathrm{Fe}_{2} \mathrm{O}_{3}$ complexes combined with magnetic fluid hyperthermia selectively target liver cancer cells. World Journal of Gastroenterology, 2009, 15: 2995-3002.

[147] J. Li, F. Jiang, B. Yang, et al., Topological insulator bismuth selenide as a theranostic platform for simultaneous cancer imaging and therapy. Scientific Reports, 2013, 17: 1998.

[148] M. Hossain, Y. Luo, Z. Sun, et al., X-ray enabled detection and eradication of circulating tumor cells with NPs. Biosensors and Bioelectronics, 2012, 38: 348-354.

[149] J.M. Kinsella, R.E. Jimenez, P.P. Karmali, et al., X-ray computed tomography imaging of breast cancer by using targeted peptide-labeled bismuth sulfide NPs. Angewandte Chemie International Edition in English, 2011, 51: 1230812311.

[150] M. Chu, X. Pan, D. Zhang, et al., The therapeutic efficacy of CdTe and CdSe quantum dots for photothermal cancer therapy. Biomaterials, 2012, 33: 7071-7073.

[151] J. Ruan, H. Song, Q. Qian, et al., HER2 monoclonal antibody conjugated RNase-A-associated CdTe quantum dots for targeted imaging and therapy of gastric cancer. Biomaterials, 2012, 33: 7093-7102.

[152] Y. Wang, Y. Zhang, Z. Du, et al., Detection of micrometastases in lung cancer with magnetic NPs and quantum dots. International Journal of Nanomedicine, 2012, 7: 2315-2324.

[153] A. Sharma, C.M. Pandey, G. Sumana, et al., Chitosan encapsulated quantum dots platform for leukemia detection. Biosensors and Bioelectronics, 2012, 38: 107113.

[154] C.Y. Tian, W.W. Zhao, J. Wang, et al., Amplified quenching of electrochemiluminescence from CdS sensitized $\mathrm{TiO} 2$ nanotubes by CdTe-carbon nanotube composite for detection of prostate protein antigen in serum. Analyst, 2012, 137: 3070-3075.

[155] H.J. Hu, S.G. Li, J. Liu, et al., Detection of the expression of HER2 using CdTe/ZnSe core/shell quantum dots as fluorescence probe in breast cancer cells. Zhonghua Bing Li Xue Za Zhi, 2011, 40: 484-486.

[156] V.A. Gérard, C.M. Maguire, D. Bazou, et al., Folic acid modified gelatine coated quantum dots as potential reagents for in vitro cancer diagnostics. Nanobiotechnology, 2011, 9: 50 .

[157] S. Steponkiene, S. Kavaliauskiene, R. Purviniene, et al., Quantum dots affect expression of CD133 surface antigen in melanoma cells. International Journal of Nanomedicine, 2011, 6: 2437-2444.

[158] V. Morosini, T. Bastogne, C. Frochot, et al., Quantum dot-folic acid conjugates as potential photosensitizers in photodynamic therapy of cancer. Photochemical \& Photobiological Sciences, 2011, 10: 842-851.

[159] A. Rakovich, T. Rakovich, V. Kelly, et al., Photosensitizer methylene blue-semiconductor nanocrystals hybrid system for photodynamic therapy. Journal of Nanoscience and Nanotechnology, 2010, 10: 2656-2662.

[160] I.V. Sukhorukova, I.Y. Zhitnyak, A.M. Kovalskii, et al., Boron nitride NPs with a petal-like surface as anticancer drug-delivery systems. ACS Applied Material Interfaces, 2015, 31. PMID: 26192448.

[161] M.J. Luderer, P. de la Puente, and A.K. Azab, Advancements in tumor targeting strategies for boron neutron capture therapy. Pharmaceutical Research, 2015, 32: $2824-2836$.
[162] C.F. Wang, M.P. Sarparanta, E.M. Mäkilä, et al., Multifunctional porous silicon NPs for cancer theranostics. Biomaterials, 2015, 48: 108-118.

[163] C. Printz, Arsenic nanoparticle holds promise in blocking aggressive breast cancer. Cancer, 2010, 116: 5567.

[164] R.L. Cunha, I.E. Gouvea, and L. Juliano, A glimpse on biological activities of tellurium compounds. Anais da Academia Brasileira de Ciências, 2009, 81: 393-407.

[165] D.B. Louria, M.M. Joselow, and A.A. Browder, The human toxicity of certain trace elements. Annals of Internal Medicine, 1972, 76: 307-319.

[166] A. Sadaf, B. Zeshan, Z. Wang, et al., Toxicity evaluation of hydrophilic CdTe quantum dots and CdTe@ $\mathrm{SiO}_{2} \mathrm{NPs}$ in mice. Journal of Nanoscience and Nanotechnology, 2012, 11: 8287-8292.

[167] F. Liu, Y. Zhang, S. Ge, et al., Magnetic graphene nanosheets based electrochemiluminescence immunoassay of cancer biomarker using CdTe quantum dots coated silica nanospheres as labels. Talanta, 2012, 99: 512-519.

[168] S.B. Rizvi, L. Yildirimer, S. Ghaderi, et al., A novel POSS-coated quantum dot for biological application. International Journal of Nanomedicine, 2012, 7: 39153927.

[169] B. Sredni, Immunomodulating tellurium compounds as anti-cancer agents. Seminars in Cancer Biology, 2012, 22: 60-69.

[170] B. Sredni, A. Shani, R. Catane, et al., Predominance of TH1 response in tumor-bearing mice and cancer patients treated with AS101. Journal of the National Cancer Institute, 1996, 88: 1276-1284.

[171] B. Sredni, R. Gal, I.J. Cohen, et al., Hair growth induction by the Tellurium immunomodulator AS101: association with delayed terminal differentiation of follicular keratinocytes and ras-dependent up-regulation of KGF expression. FASEB Journal, 2004, 18: 400-402.

[172] S.L. Goodman, M. Picard, Integrins as therapeutic targets. Trends in Pharmacological Sciences, 2012, 33: 405-412.

[173] B.J. Allen, S. Rizvi, Y. Li, et al., In vitro and preclinical targeted alpha therapy for melanoma, breast, prostate and colorectal cancers. Critical Reviews in Oncology/ Hematology, 2001, 39: 139-146.

[174] M. Hossain, M. Su, Nanoparticle location and material dependent dose enhancement in X-ray radiation therapy. Journal of Physical Chemistry C: Nanomaterials and Interfaces, 2012, 116: 23047-23052.

[175] P. Nazari, R.D. Bazaz, M.R. Mofid, et al., The antimicrobial effects and metabolomic footprinting of carboxyl-capped bismuth NPs against Helicobacter pylori. Applied Biochemistry and Biotechnology, 2014, 172: 570579.

[176] H. Zeng, G.F. Combs Jr., Selenium as an anticancer nutrient: roles in cell proliferation and tumor cell invasion. Journal of Nutritional Biochemistry, 2008, 19: 1-7.

[177] G. Schrauzer, Selenium yeast: composition, quality, analysis, and safety. Pure Applied Chemistry, 2006, 78: 105-109.

[178] G. Dennert, M. Zwahlen, M. Brinkman, et al., Selenium for preventing cancer. Cochrane Database of Systematic Reviews, 2011, 11 (5): CD005195.

[179] H. Tapiero, D.M. Townsend, K.D. Tew, The antioxidant role of selenium and seleno-compounds. Biomedicine \& Pharmacotherapy, 2003, 57: 134-144.

[180] C.D. Davis, P.A. Tsuji, and J.A. Milner, Selenoproteins and cancer prevention. Annual Review of Nutrition, 2012, 21: 73-95.

[181] P.A. Sheridan, N. Zhong, B.A. Carlson, et al., Decreased selenoprotein expression alters the immune response during influenza virus infection in mice. Journal of Nutrition, 2007, 137: 1466-1471. 
[182] L.B. Yang, Y.H. Shen, A.J. Xie, et al., Synthesis of Se NPs by using TSA ion and its photocatalytic application for decolorization of cango red under UV irradiation. Materials Research Bulletin, 2008, 43: 572-582.

[183] T. Takahashi, S. Yagi, T. Sagawa, et al., X-ray photoemission study of orthorhombic selenium; a new allotrope of crystalline selenium. Journal of the Physical Society of Japan, 1985, 54: 1018-1022.

[184] J. Zhang, X. Wang, and T. Xu, Elemental selenium at nano size (Nano-Se) as a potential chemopreventive agent with reduced risk of selenium toxicity: comparison with se-methylselenocysteine in mice. Toxicological Sciences, 2007, 101: 22-31.

[185] J.S. Zhang, X.Y. Gao, L.D. Zhang, et al., Biological effects of a nano red elemental selenium. Biofactors, 2001, 15: 27-38.

[186] Y. Zhang, X. Li, Z. Huang, et al., Enhancement of cell permeabilization apoptosis-inducing activity of selenium NPs by ATP surface decoration. Nanomedicine, 2013, 9: 74-84.

[187] Y. Ren, T. Zhao, G. Mao, et al., Antitumor activity of hyaluronic acid-selenium NPs in Heps tumor mice models. International Journal of Biological Macromolecules, 2013, 57: 57-62.

[188] C. Ramamurthy, K.S. Sampath, P. Arunkumar, et al., Green synthesis and characterization of selenium NPs and its augmented cytotoxicity with doxorubicin on cancer cells. Bioprocess and Biosystems Engineering, 2013, 3: 1131-1139.

[189] M.H. Yazdi, M. Mahdavi, E. Kheradmand, et al., The preventive oral supplementation of a selenium nanoparticle-enriched probiotic increases the immune response and lifespan of $4 \mathrm{~T} 1$ breast cancer bearing mice. Arzneimittelforschung, 2012, 62: 525-531.

[190] M.H. Yazdi, M. Mahdavi, B. Varastehmoradi, et al., The immunostimulatory effect of biogenic selenium NPs on the 4T1 breast cancer model: an in vivo study. Biological Trace Element Research, 2012, 149: 22-28.

[191] M.H. Yazdi, M. Mahdavi, N. Setayesh, et al., Selenium nanoparticle-enriched Lactobacillus brevis causes more efficient immune responses in vivo and reduces the liver metastasis in metastatic form of mouse breast cancer. DARU Journal of Pharmaceutical Sciences, 2013, 21(1): 33.

[192] D. Sun, Y. Liu, Q. Yu, et al., The effects of luminescent ruthenium(II) polypyridyl functionalized selenium NPs on bFGF-induced angiogenesis and AKT/ERK signaling. Biomaterials, 2013, 34: 171-80.

[193] S. Zheng, X. Li, Y. Zhang, et al., PEG-nanolized ultrasmall selenium NPs overcome drug resistance in hepatocellular carcinoma HepG2 cells through induction of mitochondria dysfunction. International Journal of Nanomedicine, 2012, 7: 3939-3949.

[194] B. Yu, Y. Zhang, W. Zheng, et al., Positive surface charge enhances selective cellular uptake and anticancer efficacy of selenium NPs. Inorganic Chemistry, 2012, 20: 89568963.

[195] W. Liu, X. Li, Y.S. Wong, et al., Selenium NPs as a carrier of 5-fluorouracil to achieve anticancer synergism. ACS Nano, 2012, 6: 6578-6591.

[196] Y.J. Choi, Y.J. Kim, J.W. Lee, et al., Cyto-/genotoxic effect of CdSe/ZnS quantum dots in human lung adenocarcinoma cells for potential photodynamic UV therapy applications. Journal for Nanoscience and Nanotechnology, 2012, 12: 2160-2168.

[197] F. Yang, Q. Tang, X. Zhong, et al., Surface decoration by Spirulina polysaccharide enhances the cellular uptake and anticancer efficacy of selenium NPs. International Journal of Nanomedicine, 2012, 7: 835-844.
[198] X. Gao, H. Zhang, Y. Li, et al., Mn-doped ZnSe d-dotsbased $\alpha$-methylacyl-CoA racemase probe for human prostate cancer cell imaging. Analytical and Bioanalytical Chemistry, 2012, 402: 1871-1877.

[199] L. Hong, Z. Wang, L. Yuan, et al., Subcellular distribution of CdSe quantum dots (QDs) in breast cancer cells. Journal for Nanoscience and Nanotechnology, 2012, 12: 365-367.

[200] K.K. Vekariya, J. Kaur, K. Tikoo. ER $\alpha$ signaling imparts chemotherapeutic selectivity to selenium NPs in breast cancer. Nanomedicine, 2012, 8: 1125-1132.

[201] L. Kong, Q. Yuan, H. Zhu, et al., The suppression of prostate LNCaP cancer cells growth by Selenium NPs through Akt/Mdm2/AR controlled apoptosis. Biomaterials, 2011, 32: 6515-6522.

[202] H. Luo, F. Wang, Y. Bai, et al., Selenium NPs inhibit the growth of HeLa and MDA-MB-231 cells through induction of S phase arrest. Colloids and Surfaces B: Biointerfaces, 2012, 1: 304-308.

[203] M. Shakibaie, H. Forootanfar, K.M. Moghaddam, et al., Green synthesis of gold NPs by the marine microalga Tetraselmis suecica. Biotechnology and Applied Biochemistry, 2010, 57: 71-75.

[204] M.M.S. Dallal, M.H. Yazdi, M. Holakuyee, et al., Lactobacillus casei ssp.casei induced Th1 cytokine profile and natural killer cells activity in invasive ductal carcinoma bearing mice. Iranian Journal of Allergy, Asthma and Immunology, 2012, 11: 183-189.

[205] M.H. Yazdi, M.M.S. Dallal, Z.M. Hassan, et al., Oral administration of Lactobacillus acidophilus induces IL-12 production in spleen cell culture of BALB/c mice bearing transplanted breast tumour. British Journal of Nutrition, 2010, 104: 227-232.

[206] E. Faghfuri , M.H. Yazdi, M. Mahdavi et al., Doseresponse relationship study of selenium NPs as an immunostimulatory agent in cancer-bearing mice. Archive in Medical Researches, 2015, 46: 31-37.

[207] S. Chatterjee, S. Kundu, and A. Bhattacharyya, Mechanism of cadmium induced apoptosis in the immunocyte. Toxicology Letter, 2008, 177: 83-89.

[208] N. Pathak, S. Khandelwal, Role of oxidative stress and apoptosis in cadmium induced thymic atrophy and splenomegaly in mice. Toxicology Letter, 2007, 169: 95108.

[209] A.C. Uğuz, M. Naziroğlu, J. Espino, et al., Selenium modulates oxidative stress-induced cell apoptosis in human myeloid HL-60 cells through regulation of calcium release and caspase- 3 and -9 activities. Journal of Membrane Biology, 2009, 232: 15-23.

[210] M. Shakibaie, A.R. Shahverdi, M.A. Faramarzi, et al., Acute and subacute toxicity of novel biogenic selenium NPs in mice. Pharmaceutical Biology, 2013, 51: 58-63.

[211] C.C. Liang, A.Y. Park, J.L. Guan, In vitro scratch assay: a convenient and inexpensive method for analysis of cell migration in vitro. Nature Protocols, 2007, 2: 329-333.

[212] V. Jamier, L.A. Ba, and C. Jacob, Selenium- and tellurium-containing multifunctional redox agents as biochemical redox modulators with selective cytotoxicity. Chemistry, 2010, 16: 10920-10928.

Copyright $(2016$ Mohammad Hossein Yazdi, Zargham Sepehrizadeh, Mehdi Mahdavi, Ahmad Reza Shahverdi, and Mohammad Ali Faramarzi. This is an open-access article distributed under the terms of the Creative Commons Attribution License, which permits unrestricted use, distribution, and reproduction in any medium, provided the original author and source are credited. 